\title{
Códigos de conducta y derechos laborales en maquilas de México y Guatemala*
}

\author{
César A. Rodríguez Garavito ${ }^{1}$
}

\begin{abstract}
In recent years, monitoring systems have been implemented to verify the application of corporate codes of conduct of labor conditions. This article places the codes in a wider debate about global governance and defends a participative approach to international labor standards in order to give workers a deeper awareness of their rights and power. Following an ethnographic research in clothing sweatshops in Mexico and Guatemala, the author explores the effects of code supervision on the empowerment of workers and on the labor conditions of global factories in addition to highlighting the political and institutional strategies that support the protection of labor rights.
\end{abstract}

\section{Introducción}

El tema de la protección de los derechos de los trabajadores se encuentra en nuestros días en el centro de los debates académicos y sobre políticas públicas relacionados con la globalización. En la medida en que la integración económica y el desarrollo basados en la exportación de bienes y servicios se han expandido en todo el mundo durante las últimas tres décadas, los académicos, los activistas y los gobiernos se han preocupado cada vez más por los efectos que tienen esos procesos en las condiciones laborales, especialmente en el Sur Global. De hecho, las cada vez más abundantes pruebas sobre las condiciones de explotación laboral en las fábricas globales, que abarcarían desde el acoso sexual y el abuso

\footnotetext{
${ }^{*}$ El original de este artículo se publicó con el nombre de "Global Governance and Labor Rights: Codes of Conduct and Anti-Sweatshop Struggles in Global Apparel Factories in Mexico and Guatemala”, en la revista Politics \& Society, vol. 33, n 2, junio 2005, pp. 203-233. Traducción: Carlos F. Morales de Setién Ravina.

${ }^{1}$ Agradezco los comentarios a versiones preliminares de este artículo a Luis Carlos Arenas, Nicole Breazeale, Jane Collins, Archon Fung, Kate McCoy, Pablo Mitnik, Alfonso Morales, Jamie Peck, Jeff Rothstein, Dara O’Rourke, Ronen Shamir, Gay Seidman, Matt Vidal, Erik Olin Wright y Jonathan Zeitlin. También agradezco al fondo Tinker-Nave de la Universidad de Wisconsin-Madison y al Institute for Law and Society de la Universidad de Nueva York por haber contribuido a la financiación de los viajes necesarios para la investigación de campo.
} 
físico contra las mujeres trabajadoras en las fábricas del vestido en América Central y China hasta el uso del trabajo infantil en las fábricas de balones de fútbol en Pakistán, han convertido el trabajo en las maquilas ${ }^{2}$ en el objeto de discusiones académicas y políticas exaltadas en torno a la regulación de la economía global. ${ }^{3}$ Esa evidencia también ha estimulado la formación de redes de activismo transnacionales (RATN) en las que confluyen una amplia variedad de actores y estrategias que pretenden reestablecer el vínculo entre marcas comerciales y vendedores en el Norte, por un lado, y los trabajadores que se encuentran en las fábricas suministradoras del Sur, por otro; vínculo que se ha venido desdibujando como consecuencia de la producción global descentralizada. Por ejemplo, organizaciones no gubernamentales (ONG), sindicatos de trabajadores, asociaciones de estudiantes, grupos de consumidores y organizaciones de apoyo a los trabajadores han forjado alianzas transnacionales entre consumidores y trabajadores con el propósito de presionar a las empresas transnacionales (ET) para que cumplan con los estándares laborales internacionales, a través de estrategias diversas como los boicots o la supervisión conjunta de las condiciones laborales en las fábricas suministradoras ${ }^{4}$. Recientemente, la visibilidad económica y política de estas y otras iniciativas ha aumentado aún más como consecuencia de la incorporación del problema del trabajo en las maquilas a las discusiones sobre el comercio justo, el consumismo ético y la responsabilidad social empresarial. $^{5}$

\footnotetext{
${ }^{2}$ El sustantivo "sweatshop” no tiene traducción directa al español. Define aquellos lugares, generalmente fábricas, en los cuales los trabajadores son obligados a realizar su trabajo en duras condiciones laborales y a menudo trabajando el número de horas ilimitado que les exigen los patronos. Se ha convertido en el término más usado por los activistas para definir las condiciones de sobreexplotación obrera en el Tercer Mundo. Se traduce en el texto por el término "maquila", denominación específica de las fábricas de ensamblaje en México, para referirse a cualquier forma de explotación económica en la fabricación de productos bajo condiciones laborales abusivas en cualquier lugar del mundo. Es un uso hoy común entre las organizaciones que luchan por la defensa de los derechos de los trabajadores (N. del T.).

3 Véase, entre otros, Kimberly Elliot y Richard Freeman, Can Labor Standards Improve Under Globalization? (Washington, D.C.: Institute for International Economics, 2003); Theodore Moran, Beyond Sweatshops (Washington, D.C.: The Brookings Institution, 2002); Archon Fung, Dara O’Rourke y Charles Sabel, Can We Put an End to Sweatshops? (Boston: Beacon Press, 2001); Ellen I. Rosen, Making Sweatshops: The Globalization of the U.S. Apparel Industry (Berkeley: University of California Press, 2002); Edna Bonacich y Richard Appelbaum, Behind the Label: Inequality in the Los Angeles Apparel Industry (Berkeley: University of California Press, 2000).

${ }^{4}$ Mark Anner y Peter Evans, "Building Bridges Across a Double Divide: Alliances Between US and Latin American Labour and NGOs", Development in Practice 14, no. 1-2 (2004): 34-47; Dana Frank, "Where are the Workers in Consumer-Worker Alliances? Class Dynamics and the History of Consumer-Labor Campaigns”, Politics \& Society 31, no. 3 (2003): 363-79; Liza Featherstone y USAS, Students Against Sweatshops (Londres: Verso, 2002); Andrew Ross, ed., No Sweat: Fashion, Free Trade and the Rights of Garment Workers (Londres: Verso, 1997).

${ }^{5}$ Margaret Levi y April Linton, "Fair Trade: A Cup at a Time? “ Politics \& Society 31, no. 3 (2003): 407-32; Morton Winston, “NGO Strategies for Promoting Corporate Social Responsibility”, Ethics \& International
} 
Presionadas por las RATN durante la última década, las empresas de distintos sectores industriales han adoptado códigos de conducta que regulan las relaciones con sus suministradores del Sur. Un reciente estudio del Banco Mundial estima que existen hoy en día mil códigos corporativos que se ocupan de regular las obligaciones laborales, de derechos humanos y medioambientales de las fábricas suministradoras. ${ }^{6}$ En una encuesta entre las 500 empresas más grandes del mundo, el 98\% de las que respondieron informaban tener un código de ética o directrices similares, y dos tercios de las empresas los habían adoptado durante los años noventa. ${ }^{7}$ Igualmente, numerosos sindicatos y ONG en el Norte y en el Sur han acogido los códigos de conducta como un mecanismo potencialmente valioso para hacer respetar los derechos laborales. Desde el punto de vista de estos actores, expresado en un informe de la Maquila Solidarity Network (MSN; una red activista para la defensa de los derechos de trabajadores de las maquilas), domiciliada en Toronto, "para las organizaciones laborales y no gubernamentales del Norte y del Sur la verdadera cuestión no es si apoyan o se oponen a los códigos voluntarios de conducta, sino como asumirlos de una manera efectiva y usar esos nuevos instrumentos normativos para impulsar un mayor respeto por los derechos de los trabajadores”. ${ }^{8}$

A pesar de la proliferación de códigos de conducta y sistemas de monitoreo y del interés creciente que despiertan en los círculos corporativos, laborales y de las ONG, sorprendentemente hay muy poca investigación empírica sobre el cumplimiento de los códigos y el funcionamiento de los esquemas de monitoreo. ${ }^{9}$ Los trabajos académicos existentes se componen en su mayor parte de estudios del texto de los códigos, de las negociaciones en el mundo desarrollado entre los activistas y las empresas que llevaron a la adopción de los códigos, y del proceso de establecimiento de estándares en sistemas de

Affairs 16, no. 1 (2002): 71-87; Daniel Litvin, Empires of Profit: Commerce, Conquest and Corporate Responsibility (Nueva York: Texere, 2003).

${ }^{6}$ World Bank, "Company Codes of Conduct and International Standards: An Analytical Comparison" (octubre 2003), 2.

${ }^{7}$ Andrew Wilson y Chris Gribben, Business Responses to Human Rights (Ashridge: Ashridge Centre for Human Rights, 2000), 9.

${ }^{8}$ MSN, "Codes Update”, $\mathrm{n}^{\circ} 13$ (www.maquilasolidarity.org, 2003). Para el aspecto sindical, véase Neil Kearney y Judy Gearhart, "Workplace Codes as Tools for Workers," Development in Practice 14, no. 1-2 (2004): 216-23.

9 Algunas excepciones destacadas son las de Dara O’Rourke, "Monitoring the Monitors: A Critique of Corporate Third-Party Monitoring”, en R. Jenkins, R. Pearson, y G. Seyfang, (eds.), Corporate Responsibility and Labor Rights: Codes of Conduct in the Global Economy (Londres: Earthscan, 2002): 196-208; Dara O’Rourke, "Outsourcing Regulation: Analyzing Non-Governmental Systems of Labor Standards Monitoring”, Policy Studies Journal 31 (2003): 1-29; Jill Esbenshade, "The Private Social Accountability Contract: Private Monitoring from Los Angeles to the Global Apparel Industry”, Labor Studies Journal (Spring 2001): 98-120. 
monitoreo. ${ }^{10}$ Por lo tanto, carecemos de evidencias sobre el funcionamiento de los códigos de conducta y de los sistemas de monitoreo en los lugares en los que se aplican, sobre la forma en que son utilizados los códigos por los actores locales (trabajadores, sindicatos, ONG, funcionarios estatales, empresas y asociaciones empresariales) y, lo que es aún más importante, sobre los efectos reales de los códigos en el cumplimiento de los derechos laborales en las fábricas globales y los países en los que están situadas.

En concreto, a pesar de los recurrentes lamentos en los trabajos académicos de que "la voz de los trabajadores de los países en vías de desarrollo" es el "elemento ausente” en el debate ${ }^{11}$ y de que "es primordial que estén presentes las voces de los trabajadores de los países en vías de desarrollo " en el proceso, ${ }^{12}$ está aún por estudiarse cómo las voces de los trabajadores se incluyen o excluyen en la práctica en los procesos de establecimiento y cumplimiento de los códigos de conducta, y si los códigos de conducta permiten o no a los trabajadores organizarse y consolidar sus voces en éste y otros debates, y cómo lo hacen. El trabajo académico es, consecuentemente, un reflejo de la atención preferente que la mayoría de sistemas de monitoreo de los códigos de conducta le prestan a los llamados "derechos individuales"13 (que se ocupan de cuestiones como la salud y la seguridad en el trabajo, las horas de trabajo extraordinarias, el salario mínimo y asuntos similares), en detrimento de los "derechos colectivos" (es decir, la libertad de asociación y el derecho a la negociación colectiva). Puesto que, como nos dicen Elliot y Freeman, "estos 'derechos colectivos' permitirían a los trabajadores de las maquilas decidir por sí mismos qué cuestiones abordar, qué concesiones realizar y qué luchas emprender contra sus empleadores, y probablemente harían más por mejorar los estándares laborales que cualquier otra cosa que podamos pensar", ${ }^{14}$ la falta de estudios sobre los efectos de los códigos en el empoderamiento de los trabajadores es una omisión importante en las obras académicas.

10 Tim Bartley, "Certifying Forests and Factories: States, Social Movements, and the Rise of Private Regulation in the Apparel and Forest Product Fields, "Politics \& Society 31, no. 3 (2003): 433-64; Litvin, Empires of Profit; Fung, O’Rourke y Sabel, Can We Put an End to Sweatshops?

${ }^{11}$ Elliot y Freeman, Can Labor Standards Improve Under Globalization?, 69.

${ }^{12}$ Fung, O'Rourke y Sabel, Can We Put an End to Sweatshops?, 28.

${ }^{13}$ Las expresiones usadas en el texto original, "protecting rights" y "enabling rights" no se corresponden exactamente con los conceptos del derecho laboral de tradición europea "derechos individuales" y "derechos colectivos" respectivamente. Los conceptos ingleses definen más bien un derecho en función del grado de poder que concede al trabajador en su relación laboral. Sin embargo, en el contexto del artículo del pfr. Rodríguez Garavito, las expresiones castellanas reflejan bien el tipo de derechos que están en discusión (N. del T.).

${ }^{14}$ Elliot y Freeman, Can Labor Standards Improve Under Globalization?, 31. 
El análisis de los códigos en acción arroja también una nueva luz sobre los debates teóricos más generales, porque los códigos de conducta son el ejemplo cardinal de una perspectiva sobre la regulación que se ha teorizado recientemente gracias a un abundante trabajo académico acerca de la gobernanza en la economía global. Como se explicará posteriormente, los académicos de diferentes campos del conocimiento han propuesto novedosas formas de regulación de la economía que se basan en la coordinación entre actores no estatales (empresas, asociaciones secundarias, ONG, etc.), en lugar de en la regulación estatal jerárquica. La inspiración principal de esta línea de investigación es la teorización de la colaboración entre actores no estatales como un tercer tipo de mecanismo de coordinación (junto al mercado y al Estado) que tendría el potencial de solucionar algunos de los dilemas regulatorios planteados por la globalización. Sin embargo, como ha señalado Jessop, las obras académicas que apoyan este "progreso del paradigma de la gobernanza” se concentran en las promesas del modelo y no se han ocupado suficientemente de las tensiones y los dilemas de la gobernanza. ${ }^{15}$ Puesto en otros términos, mientras que “el fracaso del mercado” y el "fracaso del Estado” se han conceptualizado y documentado profusamente, todavía está pendiente teorizar y examinar empíricamente el fracaso de la gobernanza. En particular, el paradigma de la gobernanza apenas se ha ocupado (cuando no prescindido explícitamente) de los problemas creados por las grandes asimetrías de poder entre actores no estatales (que en el caso de los códigos de conducta son los trabajadores del Sur y ET del Norte) que se supone deben apropiarse de la deliberación y la colaboración en los sistemas de gobernanza. En el campo específico de los códigos de conducta, esta omisión se refleja en la falta de atención a la libertad de asociación y negociación colectiva, que son los mecanismos institucionales esenciales mediante los que puede otorgarse poder a los trabajadores y mitigar así las asimetrías de poder.

En este artículo, pretendo contribuir a las propuestas de solución de estas deficiencias empíricas y teóricas situando los derechos colectivos en el centro del debate sobre los códigos de conducta, y trayendo a un primer plano la cuestión de las asimetrías de poder en las discusiones sobre gobernanza. Apoyándome en mis investigaciones etnográficas en México y Guatemala sobre el cumplimiento de los códigos de conducta en el sector de la fabricación del vestido y en el uso activista de los códigos por los trabajadores locales y las

\footnotetext{
${ }^{15}$ Bob Jessop, “The Rise of Governance and the Risk of Failure: The Case of Economic Development," International Social Science Journal 155 (1998): 29-45.
} 
organizaciones de apoyo a los trabajadores en alianza con las RATN, exploro el efecto de los sistemas de monitoreo de los códigos sobre las condiciones laborales y el empoderamiento del trabajador en las fábricas globales.

Mi argumento se desarrolla a partir de tres líneas. La primera es que, en contra de las afirmaciones precipitadas que descartan los códigos de conducta y sistemas de monitoreo por ser estrategias de relaciones públicas impuestas por las sedes corporativas de las empresas del Norte, ${ }^{16}$ defiendo que diferentes tipos de códigos y de sistemas de monitoreo tienen diferentes efectos sobre el cumplimiento de los derechos laborales. Mientras que los críticos tienen razón cuando dicen que la mayor parte de la industria del vestido sigue quedando fuera del alcance de cualquier sistema serio de supervisión, la evidencia de Guatemala y México sugiere que los sistemas más estrictos tienen el potencial de complementar (no de reemplazar) el derecho laboral estatal o nacional a la hora de solucionar el problema de las maquilas. La segunda línea defiende que las mejoras sostenibles de las que se beneficien los derechos individuales dentro de las fábricas globales dependen esencialmente del impulso a los derechos colectivos. Dadas las profundas asimetrías de poder entre los diversos actores en las cadenas globales de producción de bienes, a la que pertenece la industria del vestido, los cambios duraderos en las condiciones de trabajo se apoyan en el desarrollo de mecanismos institucionales dentro del sistema de monitoreo que impulsen el poder de los trabajadores y de organizaciones de apoyo a los trabajadores locales frente al de las marcas globales y las empresas suministradoras. La tercera línea de mi argumento afirma que un desplazamiento hacia sistemas de monitoreo de los códigos más efectivos y que potenciaran las capacidades de negociación de los trabajadores exigiría una presión política transfronteriza persistente. Las RATN, al dedicarse a lo que Keck y Sikkink han llamado "estrategias políticas que hacen a las empresas responsables ante la sociedad", ${ }^{17}$ actúan como fuentes esenciales de un contrapoder al obligar a las ET a que respeten sus códigos de conducta y al presionarlas para que adopten normas y métodos de vigilancia más estrictos. Los códigos de conducta, por lo tanto, deben verse como parte de un campo emergente transnacional de regulación del trabajo, que incluiría necesariamente otros tipos de estándares laborales, como las leyes estatales nacionales, los tratados internacionales, las sanciones unilaterales y las cláusulas

\footnotetext{
${ }^{16}$ Véase, por ejemplo, Trihne Duong, "Codes of Conduct Don’t Work: A View from the Factory Floor," Human Rights Dialogue 4 (2000): 5-6.

${ }^{17}$ Margaret Keck y Kathryn Sikkink, Activists Beyond Borders: Advocacy Networks in International Politics (Ithaca, NY: Cornell University Press, 1998), 24.
} 
sociales en los acuerdos comerciales, y también a las RATN, que ejercen la presión requerida para la formulación y el cumplimiento de los estándares. ${ }^{18}$

Para apoyar estas afirmaciones divido el resto de este artículo en cinco partes. En la primera parte presento el método de estudio. A continuación, explico el enfoque analítico al discutir el tratamiento de las asimetrías de poder dentro del paradigma de la gobernanza y sugiero un enfoque alternativo que destaca una forma de participación que potencia la capacidad futura de los participantes en la gobernanza de las relaciones laborales. Luego dirigiré mi atención al examen empírico de los sistemas de monitoreo del cumplimiento de los códigos de conducta y cómo se llevan a cabo en los lugares de mi investigación de campo, México y Guatemala. En la cuarta sección, explico mis ideas sobre la movilización transnacional y las estrategias políticas que hacen a las empresas responsables ante la sociedad $^{19}$ a partir de las evidencias obtenidas durante mis investigaciones sobre dos destacadas campañas de movilización transfronterizas en torno a dos productores globales: la campaña que tuvo como objetivo a Kukdong, un contratista de Nike, localizado en Puebla, México, y la campaña de Choishin, un contratista de Liz Claiborne, ubicado cerca de Ciudad de Guatemala. Finalmente, ofrezco algunas conclusiones.

\section{Método}

Este estudio es un ejemplo de lo que Marcus ha llamado "etnografía multisituada”: una combinación de métodos cualitativos aplicados al estudio de diferentes localidades que pretende examinar el funcionamiento de los procesos globales que configuran los hechos en esas localidades. ${ }^{20}$ Durante los dos viajes a los lugares de la investigación de campo que se realizaron durante esta investigación se usaron dos métodos: las entrevistas semiestructuradas y la observación participante. La gran mayoría de los datos se recogieron

\footnotetext{
${ }^{18}$ Esta perspectiva de la normativa global sobre trabajo como resultado de la lucha entre RATN y ET se desarrolla en César A. Rodríguez-Garavito, "Nike’s Law: The Anti- Sweatshop Movement, Transnational Corporations, and the Struggle over International Labor Rights in the Americas," en B. Santos y C. Rodríguez-Garavito, eds. Law and Globalization From Below: Toward a Cosmopolitan Legality (Cambridge: Cambridge University Press, 2005). Véase también David Trubek, Jim Mosher y Jeffrey Rothstein, "Transnationalism in the Regulation of Labor Relations: International Regimes and Transnational Advocacy Networks, “ Law and Social Inquiry 25 (2000): 1187-1210.

${ }^{19}$ La expresión original es “accountability politics”, traducida aquí, en el sentido del texto, por la paráfrasis "las estrategias políticas que hacen a las empresas responsables ante la sociedad”. ( $\mathrm{N}$ del T).

${ }^{20}$ George Marcus, "Ethnography in/of the World System: The Emergence of Multi-Sited Ethnography," Annual Review of Anthropology 24 (1995): 95-117.
} 
durante el segundo viaje de investigación de campo a Puebla y Ciudad de Guatemala durante el verano de 2002. Celebré entrevistas extensas con una gran variedad de personas que desempeñan importantes cargos en la industria del vestido y en los sistemas de monitoreo en México y Guatemala: representantes de las asociaciones de empresas, propietarios o administradores de las fábricas, legisladores estatales, consultores empresariales, supervisores independientes, representantes de las marcas, miembros del personal de ONG pro-trabajadores, analistas académicos, consejeros legales o líderes de sindicatos y federaciones de trabajadores. Entrevisté también a los principales actores en las campañas a favor de la sindicalización: trabajadores, líderes sindicales, administradores de las fábricas, representantes de las marcas, personal de las ONG participantes, consejeros legales y supervisores de las propias empresas e independientes. Cada una de las 34 entrevistas duró entre una y tres horas, con una media aproximada de noventa minutos. En los años 2003 y 2004 realicé también entrevistas en los Estados Unidos con miembros de los sindicatos y de las ONG involucrados en el monitoreo de los códigos de conducta, en general, y en las dos campañas a favor de la sindicalización, en particular. También mantuve entrevistas telefónicas con los trabajadores y activistas guatemaltecos que participaron en las negociaciones del año 2003 y que llevaron a la firma de un convenio colectivo en Choishin/Cimatextiles, la fábrica guatemalteca que es objeto de uno de los estudios de caso. $^{21}$ Durante el primer viaje al lugar de la investigación de campo fui también un observador-participante en la otra campaña que constituye mi otro estudio de caso: la sindicalización de los trabajadores de la fábrica de Kukdong en Puebla, México. Viajé a Puebla en marzo de 2001 y trabajé durante dos semanas con organizadores del Centro de Apoyo al Trabajador (CAT) y de United Students Against Sweatshops (USAS, una organización estudiantil que lucha por mejorar las condiciones de trabajo en las maquilas), que en ese momento se encontraban realizando el trabajo de base para la creación de un sindicato independiente en Kukdong.

Para poder tener una idea de las condiciones reales en las fábricas globales del vestido y de la manera en la que cumplen sus códigos de conducta, durante el segundo viaje de

\footnotetext{
${ }^{21}$ Las fábricas de Choishin y Cimatextiles, aunque física y legalmente independientes la una de la otra, forman en la realidad un complejo de producción único controlado por Choi \& Shin International. Por esa razón, los sindicatos de cada una de las fábricas (SINTRACHOI y SINTRACIMA, respectivamente) son producto del mismo impulso organizativo y negociaciones con las administraciones de las empresas. Sus destinos se encuentran así inextricablemente entrelazados. Para simplificar la discusión, de aquí en adelante me referiré a la fábrica como Choishin y trataré a los dos sindicatos como un único ente.
} 
campo visité varias plantas fabriles en la ciudad de Tehuacán, en el Estado de México, uno de los principales centros de producción de textiles en México. Visite también Kukdong y Choishin con la autorización de los dos fabricantes estadounidenses que son sus principales clientes (Nike y Liz Claiborne, respectivamente). Las visitas a las fábricas duraron entre tres y cuatro horas. Los administradores de las fábricas me ofrecieron una visita guiada y entrevisté al director de recursos humanos.

\section{Enfoque analítico}

\section{El paradigma de la gobernanza y los códigos de conducta}

Las recientes discusiones académicas y los experimentos prácticos sobre gobernanza comparten el diagnóstico acerca los problemas centrales de la regulación en el capitalismo contemporáneo. Según este diagnóstico, la “fracturas en la regulación” de la economía global surgen debido a la divergencia existente entre la regulación vigente y los procesos

económicos de nuestros días. ${ }^{22}$ Esa divergencia es el resultado de los diferentes niveles a los cuales funcionan los procesos económicos globales y las legislaciones estatales nacionales, y de las dificultades que enfrentan los Estados nación para aplicar su lógica normativa jerárquica, de arriba a abajo, a industrias tales como la del vestido, cuyo sistema de producción altamente descentralizado y globalizado se basa en una combinación de lógica organizativa en redes y de mercado. En este contexto, y en ausencia de mecanismos para la gobernanza global, los Estados, al intentar contrarrestar las fallas del mercado, pueden generar su propia estirpe de fallos, es decir, "las fallas del Estado". ${ }^{23}$

La pregunta guía para los teóricos de la gobernanza es si pueden establecerse instituciones reguladoras o revitalizarse las existentes de tal forma que se eviten las fallas del mercado y del Estado. Para ese enfoque, la respuesta reside en un tercer tipo de forma organizativa, es decir, en redes de cooperación que implicarían la participación activa de los actores privados: empresas, sindicatos, ONG y otras asociaciones secundarias, junto con la participación de las agencias estatales. Al seguir una lógica reflexiva que impulsa el diálogo y la innovación permanentes entre los distintos actores involucrados, estas redes, se argumenta, tienen el potencial de superar los dilemas regulatorios que los mercados (que

\footnotetext{
${ }^{22}$ Saskia Sassen, Globalization and its Discontents (Nueva York: The New Press, 1998), 155.

${ }^{23}$ Bob Jessop, The Future of the Capitalist State (Cambridge: Polity Press, 2002), 226-27.
} 
siguen la lógica del intercambio) y los Estados (que siguen la lógica de la autoridad) no pueden solucionar por sí mismos. $^{24}$

Se ha generado un enorme e influyente acervo de obras académicas durante los pasados años que desarrolla un trabajo teórico y empírico sobre el paradigma de la gobernanza bajo una variedad de denominaciones, entre las cuales estarían las de "experimentalismo democrático", 25 “derecho posregulatorio”, 26 “derecho blando”, 27 “regulación responsiva”, 28 “gobernanza en colaboración”, 29 "regulación delegada externa”, 30 “derecho reflexivo”31 o simplemente "gobernanza”. ${ }^{2}$ Apoyándose en diferentes niveles de teoría social pragmática, los analistas que contribuyen a esta línea de investigación y de políticas públicas han explorado el potencial de las recientes transformaciones en la gobernanza de las empresas (entre las cuales estarían la evaluación de las prácticas propias a partir de su comparación con las mejores prácticas sectoriales $;^{33}$ la innovación a través de la deliberación dentro de las empresas y entre ellas; la ingeniería sincrónica y la detección de errores) con el fin de solucionar los problemas regulatorios de una amplia gama de campos institucionales, que

\footnotetext{
${ }^{24}$ Jessop, The Future of the Capitalist State, 230.

${ }^{25}$ Michael Dorf y Charles Sabel, “A Constitution of Democratic Experimentalism," Columbia Law Review 98, no. 2 (1998): 267-473; Charles Sabel, "Learning by Monitoring: The Institutions of Economic Development," en Neil Smelser y Richard Swedberg, eds., The Handbook of Economic Sociology (Princeton: Princeton University Press, 1994): 137-65; Charles Sabel, "Bootstrapping Reform: Rebuilding Firms, the Welfare State, and Unions,” Politics \& Society 23, no. 1 (1995): 5-48.

${ }^{26}$ Gunther Teubner, "After Legal Instrumentalism? Strategic Models of Post- Regulatory Law," en G. Teubner, ed., Dilemmas of Law in the Welfare State (Berlin: De Gruyter, 1986): 299-326.

${ }^{27}$ Francis Snyder, "Soft Law and Institutional Practice in the European Community," en S. Martin, ed., The Construction of Europe (Boston: Kluwer, 1994): 197-227.

${ }^{28}$ Ian Ayres y John Braithwaite, Responsive Regulation: Transcending the Deregulation Debate (Nueva York: Oxford University Press, 1992).

${ }^{29}$ Jody Freeman, "Collaborative Governance in the Administrative State," UCLA Law Review 45, no. 1 (1997): 1-98.

${ }^{30}$ Dara O’Rourke, “Outsourcing Regulation”.

${ }^{31}$ Gunther Teubner, "Substantive and Reflexive Elements in Modern Law," Law and Society Review17, no. 2 (1983): 239-85; Ralf Rogowski y Ton Wilthagen, eds. Reflexive Labour Law: Studies in Industrial Relations and Employment Regulation (Boston: Kluwer, 1994).

${ }^{32}$ Michael Mac Neil, Neil Sargent, y Peter Swan, eds., Law, Regulation, and Governance (Don Mills, Ontario: Oxford University Press, 2002); Joseph Nye y John Donahue, eds., Governance in a Globalizing World (Washington, D.C.: Brookings Institution, 2000);

${ }^{33}$ La palabra inglesa que define este tipo de práctica es "benchmarking”. Su traducción es difícil y en los artículos sobre administración de empresas no se suele traducir. Hace referencia, como traduzco, a una práctica mediante la cual se evalúa una empresa comparándola con aquellas que muestran un mejor desempeño en el sector de estudio (N. del T.).
} 
irían de la reforma de las escuelas públicas a nivel local ${ }^{34}$ a la regulación medioambiental nacional, ${ }^{35}$ la coordinación regional de la regulación ${ }^{36}$ y los estándares laborales globales. ${ }^{37}$

Para aquellos que contribuyen a la formulación del paradigma, las instituciones que incorporan ese tipo innovaciones impulsan la colaboración reflexiva entre actores a todos los niveles, entre empleados y empleadores dentro de las empresas, entre las empresas y las asociaciones privadas, y entre Estados, empresas asociaciones y organizaciones internacionales. Estos esquemas institucionales, se argumenta, generan dos tipos de beneficios económicos y políticos. Primero, son más útiles para las necesidades de coordinación de los mercados globales complejos e inestables que caracterizan el capitalismo post-fordista de lo que lo son las instituciones estatales centralizadas, del tipo de “orden y control”, pensadas para regular las economías capitalistas fondistas. ${ }^{38}$ En segundo lugar, debido a los beneficios para la eficiencia económica y política que resultan del uso del conocimiento local, las instituciones públicas deben estar descentralizadas y abiertas a la participación de todos los individuos y grupos potencialmente afectados por ellas. Por consiguiente, se espera que de la democracia deliberativa surjan nuevas fuerzas en la esfera pública que incrementen la legitimidad de la acción estatal. ${ }^{39}$

Sin perjuicio de sus contribuciones a la revitalización de la reflexión sobre el problema de la regulación y la teoría democrática, el paradigma de la gobernanza ha ignorado en gran medida el problema de las diferencias de poder entre actores dentro de las instituciones democráticas deliberativas. Las profundas desigualdades que caracterizan los contextos local e internacional y que plantean los retos regulatorios más difíciles (por ejemplo, las desigualdades entre capital y trabajo en la producción globalizada) están muy lejos de las condiciones ideales de deliberación que presupone el paradigma. Algunos teóricos de la gobernanza replican que las asimetrías de poder entre actores sociales no son tan profundas como para impedir una deliberación genuina. Frente a los críticos que defienden el “igualitarismo centralista” y buscan mitigar las desigualdades en el poder de negociación

\footnotetext{
${ }^{34}$ James Liebman y Charles Sabel, “A Public Laboratory Dewey Barely Imagined: The Emerging Model of School Governance and Legal Reform,” NYU Journal of Law and Social Change 28 (2003-2004): 183-305.

35 Bradley Karkkainen, "Environmental Lawyering in the Age of Collaboration," Wisconsin Law Review 2002, no. 2: 555-74.

${ }^{36}$ Jonathan Zetlin y David Trubek, eds. Governing Work and Welfare in a New Economy: European and American Experiments (Oxford: Oxford University Press, 2003).

${ }^{37}$ Fung, O’Rourke y Sabel, Can We Put an End to Sweatshops?

${ }^{38}$ Dorf y Sabel, “A Constitution of Democratic Experimentalism”; Jessop, The Future of the Capitalist State.

${ }^{39}$ Joshua Cohen y Charles Sabel, "Directly-Deliberative Polyarchy," European Law Journal 3, no. 4 (1997):

313-42; Dorf and Sabel, "A Constitution of Democratic Experimentalism.”
} 
mediante mecanismos para la redistribución de los recursos y el poder como una precondición para la deliberación, si no se quiere que esta última alimente la cooptación y profundice la desigualdad, los defensores del modelo de la gobernanza alegan que "la política pública es enormemente más compleja y las perspectivas de los desposeídos son mucho más abiertas desde una perspectiva histórica que lo que permite pensar la idea de la reproducción mecánica de las desigualdades". ${ }^{40}$ Desde una perspectiva pragmática, los intereses y valores de los actores se definen durante el proceso de deliberación, más que estar dadas de antemano por las posiciones desiguales de los actores en el campo social. Por ello, el éxito o el fracaso de las instituciones para la gobernanza emana de las circunstancias en cada situación concreta, en vez de resultar de la existencia de un conjunto fijo de precondiciones, como podrían ser los mecanismos para compensar las diferencias de poder. Dentro de la gobernanza deliberativa, “es imposible predecir lo que harán las personas o grupos a partir de la observación de sus intereses, valores o instituciones, porque los límites de éstos pueden siempre convertirse en el punto de partida de su redefinición”. ${ }^{41}$ Como resultado, el paradigma de la gobernanza tiende a dejar a un lado las asimetrías de poder y a contemplar la esfera pública como un espacio bastante despolitizado y de colaboración entre "interesados" ${ }^{42}$ en sentido amplio.

Las contribuciones y defectos del paradigma de la gobernanza se ven reflejados en su aplicación a la cuestión de los estándares laborales internacionales, que se desarrollan sobre todo mediante el modelo de los “estándares laborales en continua mejora” (ELCM) en el que se inspirarían los códigos de conducta empresarial. ${ }^{43}$ En el modelo de los ELCM, las ET se comprometerían con los códigos y los harían cumplir a lo largo de toda su cadena de suministro global, revelarían la localización de sus fábricas suministradoras y permitirían que monitores realizaran inspecciones en ellas. Monitores independientes o contratados por las empresas harían listas en las que se clasificaría a las empresas según las condiciones laborales de sus fábricas suministradoras. Finalmente, organizaciones en las que participan una pluralidad de interesados, como la Fair Labor Association (FLA) y el Working Rights Consortium (WRC), y también organizaciones internacionales (como la Organización

\footnotetext{
${ }^{40}$ Dorf y Sabel, “A Constitution of Democratic Experimentalism,” 409.

${ }^{41}$ Sabel, "Learning by Monitoring," 158.

${ }^{42}$ El término "stakeholder" en inglés puede traducirse de una manera general por "interesado", pero el vocablo inglés define aquellos que tienen algo que perder o ganar como consecuencia de determinadas decisiones o actuaciones. La teoría social pretende con ello dar entrada en los procesos de decisión a aquellos afectados por las mismas.

${ }^{43}$ Fung, O’Rourke y Sabel, Can We Put an End to Sweatshops?
} 
Internacional del Trabajo (OIT) y el Banco Mundial), controlarían a los monitores y pondrían la información al alcance de un público más amplio. Los consumidores y los inversores usarían esta información en sus decisiones de compra e inversión respectivamente. Ello generaría incentivos de mercado para que las empresas compitieran por obtener mejores clasificaciones y de esta forma impulsarían hacia arriba los estándares laborales. $^{44}$

A través de un sistema de regulación descentralizado que promueve la transparencia y la participación de actores múltiples, el modelo de los ELCM recoge los beneficios políticos y económicos del paradigma de la gobernanza. Sin embargo, al igual que este último, ignora las profundas asimetrías de poder entre diferentes actores, especialmente entre los contratantes transnacionales y sus suministradores, por un lado, y los trabajadores y las organizaciones locales de apoyo a los trabajadores, por el otro. En el enfoque de los ELCM, que se orienta hacia las empresas, se piensa que la mejora de los estándares laborales se producirá principalmente como producto de las relaciones entre suministradores y contratantes a través de mecanismos dirigidos a la mejora de la producción, como la evaluación de las prácticas propias a partir de su comparación con las mejores prácticas sectoriales. $^{45}$ De ahí la ausencia de esquemas institucionales que incluyan como uno de los objetivos esenciales de la supervisión la participación de los trabajadores como actores fundamentales en ella o el empoderamiento de los trabajadores. Además, la presión económica y social que impulsa el proceso de los ELCM se origina principalmente a partir de decisiones de mercado de consumidores e inversores individuales éticos. Consecuentemente, la presión compensadora de carácter claramente político que podría realizar el Estado y los actores colectivos organizados (asociaciones de consumidores, sindicatos, ONG y otros similares) se ve relegada a un segundo plano.

Argumento que el dejar a un lado las asimetrías de poder es una de las fuentes principales del fracaso de la gobernanza. Como explicaré posteriormente, en el campo del cumplimiento de los códigos de conducta ello se ilustra en las limitaciones de los sistemas de monitoreo que comparten con los ELCM su relativa ignorancia de los derechos colectivos y de la presión política organizada. Ello sugiere la necesidad de un enfoque diferente a la gobernanza y a la regulación laboral global que otorgue un lugar primordial a

\footnotetext{
${ }^{44}$ Ibíd., 5.

${ }^{45}$ Archon Fung, comunicación personal al autor.
} 
las cuestiones de la presión política compensadora y a una participación de los trabajadores que les de conciencia del poder que pueden tener en las relaciones laborales.

\section{Gobernanza, regulación participativa y estándares laborales internacionales}

Algunas contribuciones al debate de la gobernanza han reconocido y buscado solucionar el riesgo de fracaso que se deriva de las diferencias de poder. Por ejemplo, la teoría de Fung y Wright de la gobernanza participativa, que hace a los participantes más conscientes de su poder, se preocupa principalmente por el papel del poder compensador dentro de los sistemas de gobernanza. ${ }^{46}$ Este enfoque comienza por reconocer la posibilidad de esquemas de gobernanza que se convierten en meros escaparates, puesto que "esos esquemas son a menudo insensibles a los problemas de falta de poder y dominación, pareciendo sugerir con ello que si construimos esquemas institucionales de la manera correcta, entonces simplemente se neutralizarán los grandes desequilibrios de poder en el contexto de estas instituciones”. ${ }^{47}$ De esta forma, se necesitan mecanismos institucionales y estrategias políticas que faciliten la aparición y el ejercicio de un contrapoder. Como lo expresan Fung y Wright, “en términos amplios, el cambio de una gobernanza adversarial jerárquica a otra gobernanza en colaboración, en la que no existe ningún poder o capacidad compensadores, puede suponer en la práctica una maniobra de desregulación, que busca la disminución del papel del Estado, en la que las fuerzas de oposición son cooptadas y neutralizadas, y la participación en colaboración se convierte en un simple escaparate”. ${ }^{48}$

Por lo tanto, en la esfera de los estándares laborales internacionales, la principal tarea teórica y práctica es pensar en formas que permitan pasar de una gobernanza elitista y orientada hacia las empresas, como la que representan actualmente la mayoría de sistemas de monitoreo, a un enfoque alternativo de los códigos, como el que representan algunas experiencias incipientes de monitoreo independiente, de empoderamiento de los

\footnotetext{
${ }^{46}$ Archon Fung y Erik Olin Wright, “Countervailing Power in Empowered Participatory Governance,” en A. Fung y E. Wright, eds. Deepening Democracy: Institutional Innovations in Empowered Participatory Governance (Londres: Verso, 2003): 259-89; Archon Fung, "Deliberative Democracy and International Labor Standards," Governance 16, no. 1 (2003): 51-71.

${ }^{47}$ Ibíd., 259.

${ }^{48}$ Ibíd., 265.
} 
trabajadores y de organización transfronteriza de los trabajadores, descritas posteriormente en este capítulo. Este modo alternativo, que defino como "regulación laboral participativa que logra el empoderamiento de los trabajadores” (RELAPET), obliga a estudiar tres fuentes potenciales de fracaso del modelo de la gobernanza. La primera, las diferencias de poder entre capital transnacional y mano de obra local, que necesitan reducirse mediante esquemas institucionales que protejan efectivamente los derechos de los trabajadores a organizarse y a negociar colectivamente. La segunda, la desigualdad de las voces entre las partes del Norte y del Sur (ONG, sindicatos, grupos de consumidores, etc.) dentro de los sistemas de monitoreo necesita solucionarse mediante normas equitativas en el proceso de decisión y nuevas formas de acuerdos transnacionales, que reemplacen la dominación actual de los actores del Norte y permitan construir las capacidades de las organizaciones de apoyo a los trabajadores en el Sur. Conjuntamente, estas dos características del modelo permiten una participación que hace conscientes de su propio poder a los trabajadores organizados, a las organizaciones de apoyo a los trabajadores locales y a las RATN, y que hace viable el requisito que exige los esquemas de la RELAPET de la existencia un poder compensador. En tercer lugar, la RELAPET complementa más que sustituye a la regulación estatal. Frente a los modelos de los códigos como el de los ELCM, que ven los estándares básicos uniformes como el producto (y no como el punto de partida) de los mecanismos de gobernanza, ${ }^{49}$ la RELAPET considera las leyes laborales nacionales y los estándares laborales internacionales mínimos (reconocidos en las convenciones de la OIT) como la base normativa a partir de la cual deben construirse y mejorarse los códigos. Me refiero a este modelo como regulación laboral participativa dirigida al empoderamiento de los trabajadores para subrayar esa interrelación y continuidad entre códigos y normativas nacional e internacional.

Por lo tanto, la aplicación de la lógica de la RELAPET a las cadenas de producción de bienes globales conlleva instituciones y presiones políticas en dos niveles: 1) Los Estados, las RATN, las organizaciones de vigilancia internacionales como la FLA o el WRC, las ET (presionando a sus suministradores) y organizaciones internacionales (por ejemplo, la OIT) crean las condiciones políticas y jurídicas que permiten que 2) los trabajadores locales, los sindicatos, las organizaciones de apoyo a los trabajadores, los empleadores y las autoridades públicas puedan ejercer una vigilancia continua y gocen de mayor poder de

\footnotetext{
${ }^{49}$ Véase Fung, O’Rourke, y Sabel, Can We Put an End to Sweatshops?, 29.
} 
negociación con respecto a las condiciones laborales. Como veremos luego, los sindicatos de Choishin y Kukdong fueron el producto de esta combinación precisa de presiones compensadoras y deliberación y negociación locales en las que podían observarse a un mismo tiempo tácticas de oposición y de colaboración.

El argumento a favor de un enfoque de RELAPET a los códigos de conducta se basa en última instancia en la creencia de que las mejoras sostenibles de las condiciones laborales en las fábricas globales dependen del empoderamiento de los trabajadores. Los derechos colectivos, al permitirles a los trabajadores que decidan por sí mismos el contenido y al ritmo de sus luchas con los empleadores, y que participen activamente en una supervisión verdaderamente continua del funcionamiento diario de la fábrica, son la clave para obtener beneficios duraderos para los derechos individuales. Así, el argumento a favor de la RELAPET no reside sólo en los beneficios intrínsecos de la democracia política y económica mejorada producto de la organización de los trabajadores, sino también del vínculo esencial entre derechos colectivos y mejoras tangibles y sostenibles en las condiciones laborales dentro de las fábricas globales.

La esfera pública global contemplada por la RELAPET es una esfera politizada. Aunque al igual que en el paradigma de la gobernanza, la colaboración y el diálogo entre actores privados organizados (y entre ellos y los Estados y las organizaciones interestatales) tiene un papel importante, el trasfondo de esta participación es una sociedad civil global movilizada en la cual las RATN y los movimientos sociales ejercen presión sobre las ET, los suministradores, los Estados y otros actores dominantes mediante una política de oposición. Las campañas informativas, los boicots, la educación del público y otras tácticas de oposición son tan relevantes como la deliberación en colaboración, el consumo y la inversión con carácter ético. ${ }^{50}$

Las siguientes secciones exponen razonadamente el análisis crítico del enfoque prevaleciente en relación con los códigos y los signos emergentes de una RELAPET alternativa a partir de las realidades de la supervisión y la organización obrera en las fábricas globales de México y Guatemala.

\section{Códigos en acción: contexto y funcionamiento de los sistemas de monitoreo}

\footnotetext{
${ }^{50}$ Véase Rodríguez Garavito, “Nike’s Law.”
} 
Los críticos que se sitúan en los lados opuestos del espectro teórico y político han descartado ambos los códigos de conducta por razones opuestas. Por un lado, los entusiastas de la globalización han condenado los códigos estrictos porque amenazan con interferir en el flujo plácido del comercio y de la inversión que se supone son las mejores palancas para elevar los estándares laborales en el Sur. ${ }^{51}$ Por otro lado, algunos críticos progresistas, impacientes frente a las realidades de la cooptación y la fachada de regulación que caracterizan los sistemas elitistas de la gobernanza, han rechazado los códigos de conducta por considerarlos estrategias de relaciones públicas orquestadas por las ET en cooperación con ONG y grupos de consumidores favorables al gobierno del mercado. ${ }^{52}$

¿Qué es lo que nos dice la evidencia en México y Guatemala acerca de estas críticas? En esta sección, abordo esta cuestión estudiando primero los obstáculos políticos y económicos a la regulación estatal efectiva que han llevado a los sindicatos y a las organizaciones de apoyo a los trabajadores en México y Guatemala a experimentar con el uso de los códigos. Estudio a continuación varios sistemas de monitoreo y examino su diferente impacto en el empoderamiento de los trabajadores y en la posibilidad de producir mejoras sostenibles de las condiciones laborales en las fábricas globales.

\section{¿Por qué existen los códigos de conducta?}

Uno de los pocos puntos de consenso que pueden observarse en las entrevistas con los líderes sindicales, propietarios de fábricas, monitores independientes o contratados por las empresas, representantes de las marcas y activistas obreros en México y Guatemala es que, tal y como están las cosas en este momento, el Estado no es un verificador fiable del cumplimiento de las normas laborales. Incluso aquellos que descartan los códigos de conducta de antemano, como el secretario de la CUSG, una federación obrera guatemalteca para la cual los códigos son una "farsa”, no tienen prácticamente ninguna esperanza en el Estado como único regulador de las condiciones laborales en las fábricas globales. ${ }^{53}$ En el caso de Guatemala, un país en reconstrucción tras casi cuatro décadas de guerra civil, las

\footnotetext{
${ }^{51}$ Jagdish Bhagwati, "Why Nike is on the Right Track" (www.columbia.edu/ jb38, 2000)

${ }^{52}$ Una ácida y compleja valoración teórica de este tipo es la de Ronen Shamir, "Corporate Social Responsibility: A Case of Hegemony and Counter-Hegemony,” en B. Santos y C. Rodríguez Garavito, eds. Law and Globalization From Below.

${ }^{53}$ Entrevista con el secretario general de la CUSG, Ciudad de Guatemala, 1 de agosto de 2002.
} 
dificultades que supone construir instituciones estatales capaces de hacer cumplir derechos laborales a corto plazo están decididamente ilustradas por el comentario del adjunto para asuntos laborales de la Misión de Verificación de Naciones Unidas en Guatemala (MINUGUA), que ha sido responsable de vigilar el cumplimiento de las reformas del derecho laboral ordenadas por los Acuerdos de Paz de 1996:

\begin{abstract}
"No hay soluciones mágicas ni atajos. Se podría decir: "Bueno, lo que debemos hacer es mejorar los tribunales laborales". Perfecto. Creemos otros 20 tribunales. Estupendo. Pero, ¿dónde están los jueces? ¿Van a salir de un platillo volante? ¿Van a venir de la comunidad internacional? ¿Es que vamos a tener a un juez noruego como titular de un tribunal en Guatemala? En este país no hay escuelas para formar jueces laborales, no hay ninguna escuela de jueces, seamos claros. Y no pueden existir porque no existen académicos... todo quedó destruido por la guerra. Llevamos 30 o 40 años de atraso...así que las cosas no van a cambiar de la noche a la mañana”. ${ }^{4}$
\end{abstract}

A la luz de esta situación, las organizaciones activistas laborales internacionales y nacionales tienden a tener una visión pesimista de las perspectivas para mejorar la capacidad reguladora del Estado en el futuro cercano y contemplan, aunque sea dubitativamente, la posibilidad de comprometerse con formas no estatales de regulación. Ello ha conducido a los analistas a concluir que la capacidad estatal limitada, exacerbada por las políticas neoliberales, es una de las razones esenciales por las cuales la gobernanza en colaboración ha ganado fuerza. ${ }^{55}$ Sin embargo, esta conclusión necesita matizarse, porque tiende a aceptar con exceso de precipitación la idea de que la incapacidad del Estado surge naturalmente de las transformaciones actuales de la economía global. De hecho, la (in)capacidad del Estado es el resultado de prácticas y discursos a los que contribuyen activamente las elites estatales, y está lejos de ser homogénea entre los distintos países, aun dentro del mismo Sur Global. ${ }^{56}$ Mientras que algunos países como Guatemala se enfrentan al tipo de problemas infraestructurales fundamentales que nos sugiere la cita referida, otros como México pueden confiar en un aparato estatal que, si se pone al servicio de la protección de los derechos laborales, puede conseguir un nivel mucho más alto de cumplimiento. De esta forma, la utilidad y la conveniencia de los códigos de

\footnotetext{
${ }^{54}$ Entrevista con Ricardo Changala, Ciudad de Guatemala, 2 de agosto de 2002 (énfasis suyo).

${ }^{55}$ Véase, por ejemplo, Bartley, "Certifying Forests and Factories."

${ }^{56}$ Véase Peter Evans, “The Eclipse of the State? Reflections on Stateness in an Era of Globalization,” World Politics 50, no. 1 (1997): 62-87.
} 
conducta como mecanismos para gobernar las relaciones laborales en contextos específicos deben considerarse como una variable más que como una constante.

En los contextos mexicanos y guatemalteco, los problemas de incapacidad del Estado son una mezcla de prácticas corruptas asociadas con relaciones corporativas entre el Estado, el capital y un movimiento obrero organizado cooptado (en México) que han producido todas ellas un mayor incentivo para que los trabajadores, sindicatos y ONG defensoras de los trabajadores experimenten con los códigos de conducta. En México, ese tipo de prácticas se extiende de las asociaciones empresariales corruptas al soborno de los jueces e inspectores de trabajo. ${ }^{57}$ En Guatemala, incluiría la represión violenta de los sindicatos y un sistema informal de puerta giratoria por el cual los antiguos inspectores laborales son nombrados jefes de recursos humanos en las fábricas del vestido cuya producción está destinada a la exportación. ${ }^{58}$ Con su presencia en los muros de las oficinas de las federaciones obreras, los retratos de docenas de líderes sindicales asesinados por las fuerzas de seguridad y paramilitares durante las últimas décadas son un terrorífico recuerdo del muy alto nivel de intimidación y represión.

Una última razón que impulsa a experimentar con los códigos de conducta es la oposición concertada y a menudo violenta por parte de los propietarios y gestores de las fábricas en la industria del vestido a que los trabajadores se organicen colectivamente. La oposición irrenunciable de los propietarios mexicanos de las maquilas a la formación de sindicatos independientes está bien documentada. ${ }^{59}$ En Guatemala, los industriales luchan colectivamente con todo su poder contra los intentos de sindicalización en cualquier fábrica. El presidente de FESTRAS, la federación obrera guatemalteca que coordina el impulso sindicalista en Choishin, destacaba que "sabemos que nos enfrentamos no sólo a Choishin, sino a todo el sector textil y del vestido, así que sabemos que usarán todo tipo de

\footnotetext{
${ }^{57}$ Entrevista con Arturo Alcalde (abogado coadyuvante del sindicato), Ciudad de México, 15 de julio de 2002; entrevista con Samuel Porras (abogado del sindicato de Kukdong), Puebla, México, 15 de julio de 2002.

${ }^{58}$ Entrevista con los líderes de UNSITRAGUA (federación nacional de trabajadores), Ciudad de Guatemala, 1 agosto de 2002; entrevista con el secretario general de la CUSG.

59 Véase, por ejemplo, Huberto Juárez, Allá...donde viven los más pobres: cadenas globales y regiones productoras en la industria maquiladora del vestido (Puebla: BUAP, 2005); Dan La Botz, Mask of Democracy: Labor Supression in Mexico Today (Boston: South End Press, 1992).
} 
tácticas, no porque sea rentable para ellos... sino porque su principal fin es atacar cualquier organización obrera con el propósito de que no se siente un precedente”. 60

Entre esas tácticas conjuntas antisindicalistas se encuentra una lista negra fácilmente disponible de “personas conflictivas” y un sistema de monitoreo de los códigos de conducta organizado por VESTEX, la asociación nacional de empresas textiles y del vestido, con la intención de prevenir la aparición de otros más estrictos. Este sistema contrata auditores privados y certifica corrientemente que las fábricas cumplen con los códigos y las leyes laborales.

En resumen, la incapacidad del Estado, las prácticas del corporativismo, la represión estatal y las estrategias antisindicalistas del capital local convergen para crear un bloqueo que ha impulsado hacia la experimentación con el uso de los códigos de conducta empresarial y llevado a los activistas de los derechos laborales a buscar estrategias transnacionales. En lo que Keck y Sikkink han llamado un "efecto bumerán", ${ }^{61}$ algunos sindicatos y organizaciones de derechos laborales en los dos países han eludido al Estado nacional y establecido redes con ONG, consumidores, estudiantes, reguladores y universidades extranjeras, todas ellas bien dispuestas hacia los trabajadores, que han usado los códigos para presionar a los gobiernos y a las ET, que a su vez han presionado ocasionalmente a los legisladores y suministradores mexicanos y guatemaltecos para que respeten los derechos laborales.

\section{El monitoreo de las fábricas globales del vestido}

¿Cómo se aplican los códigos de conducta en la práctica? ¿Cuáles son los efectos de los sistemas de monitoreo en la capacidad de los trabajadores para organizarse y, por lo tanto, en sus posibilidades de conseguir mejoras duraderas en las condiciones laborales? Al ocuparme de estas cuestiones en el entorno de las fábricas globales en Guatemala y México presto atención principalmente al monitoreo por terceros independientes, que supone una forma de supervisión en la que se aplica un código de conducta elaborado por una organización coordinadora en la que participan una pluralidad de interesados, entre las cuales cabe destacar la Fair Labor Association (FLA), el Worker Rights Consortium (WRC), Social Accountability International (SAI), o el Worlwide Responsible Apparel

\footnotetext{
${ }^{60}$ Entrevista con el secretario general de FESTRAS, Ciudad de Guatemala, 29 de julio de 2002.

${ }^{61}$ Keck y Sikkink, Activists Beyond Borders, 13.
} 
Production Certification Program (WRAP). Dada la falta de credibilidad de los sistemas de vigilancia y control internos (en los que un único fabricante supervisa su cumplimiento basándose en auditorías realizadas por su propio personal o por una empresa de auditoría contratada por él) y de la vigilancia y control por terceros asociados (que implica que una asociación de empresas formule el código de conducta y contrate empresas de auditoria social que vigilen su cumplimiento), la mayoría de los debates y experimentos que están teniendo lugar giran en torno al monitoreo independiente realizado por terceros.

Los cuatro aspectos fijos en el análisis del monitoreo por terceras partes son el contenido de los códigos, la independencia y la generalidad de la supervisión, la transparencia del sistema, y las sanciones por incumplimiento. La combinación de estos factores permite una comparación que arroja un rango de sistemas que van del más restrictivo al más permisivo. Como aproximación a esta tipología y como guía para la valoración del potencial que tiene cada sistema para conseguir el empoderamiento de los trabajadores, he construido una escala de 10 puntos basada en los cuatro factores anteriormente mencionados. Cada uno de los primeros tres factores se dividen a su vez en varias preguntas, mientras que el tema de las sanciones se aborda en una sola pregunta. Por cada pregunta que se responde afirmativamente se le otorga un punto al sistema de monitoreo estudiado. Puesto que la mayoría de los sistemas comparten los principios y normas básicas, y que en obras académicas $^{62}$ se encuentra disponible un estudio general sobre los orígenes y características de los sistemas, me concentro aquí en las cuestiones acerca de las cuales difieren los distintos sistemas y que suponen una diferencia esencial en relación con los derechos colectivos. Las preguntas usadas para construir la clasificación son las siguientes:

\section{Derechos colectivos}

1.1 ¿El código incluye alguna cláusula que garantice claramente la libertad de asociación y el derecho a la negociación colectiva?

1.2 ¿El código establece un mecanismo de funcionamiento que permita a los trabajadores presentar sus quejas directamente a los supervisores o a la organización coordinadora?

\section{Independencia y generalidad del monitoreo}

2.1 ¿La organización coordinadora (en lugar del fabricante) es la que selecciona y paga a los monitores?

${ }^{62}$ MSN, “Codes Update;” O’Rourke, “Outsourcing Regulation.” 
2.2 ¿La mayoría de los monitores acreditados son organizaciones independientes (frente a empresas privadas seleccionadas directa o indirectamente por las fábricas)?

2.3 ¿Las visitas son imprevistas?

2.4 ¿El sistema implica la supervisión sistemática de un conjunto de fábricas a lo largo de toda la cadena de suministro (frente a la selección de fábricas concretas por ellas mismas o a unas pocas fábricas concretas seleccionadas por la organización coordinadora)?

2.5 ¿Las evaluaciones de las fábricas se basa en una vigilancia continua (frente a unas pocas visitas)?

3. Transparencia

3.1 ¿Se exige a los fabricantes revelar el nombre y la localización de sus fábricas suministradoras?

3.2 ¿La organización coordinadora publica periódicamente información acerca del desempeño de los fabricantes en relación con el cumplimiento de los códigos?

4. Sanciones

¿La organización coordinadora tiene el poder de imponer sanciones, más allá de negar la certificación (por ejemplo, la exclusión del sistema, la cancelación de los contratos, etc.)?

La puntuación obtenida permite realizar la comparación de los principales sistemas estadounidenses que se muestra en la Tabla 1. De izquierda a derecha, los sistemas se ordenan del más al menos riguroso. Esta comparación pretende subrayar las tendencias generales del monitoreo, más que establecer una clasificación de los sistemas existentes con precisión. Específicamente, es difícil la medición precisa de los méritos relativos de los dos sistemas más estrictos, es decir, el del WRC (fundado en 1998 a iniciativa de USAS y al que se han unido universidades y sindicatos) y el de la FLA (creado en 1996 bajo los auspicios del gobierno estadounidense y al que se han unido los principales fabricantes, pero no los sindicatos). La dificultad reside en el hecho de que representan dos enfoques diferentes a la supervisión, más que dos variedades de un mismo enfoque. El WRC no certifica fábricas o marcas comerciales, ni lleva a cabo inspecciones anuales de una muestra aleatoria de fábricas suministradoras. En lugar de ello, lleva a cabo investigaciones continuas y en profundidad de un número limitado de fábricas seleccionadas mediante un proceso que parte de las quejas presentadas por los trabajadores y las ONG locales sobre violaciones a los códigos de conducta. La industria no se ve representada en su Consejo de 
Dirección, que se compone de delegados de las administraciones universitarias, representantes de USAS y expertos laborales. Por ello, el papel del WRC ha sido numerosas veces denominado como de "contrincante",63, "vigilante"64 o "activador de alarmas”. ${ }^{65}$ En contraste, la FLA certifica las marcas mediante el monitoreo de una muestra amplia de fábricas con “alto riesgo”. Busca trabajar en colaboración con la industria, que se encuentra bien representada en su Consejo de Dirección. En abril de 2002, presionada por la competencia del WRC, la FLA realizó importantes cambios, que se reflejan en la Tabla 1, en relación con la independencia y la transparencia de su programa de monitoreo. En contraste con los términos usados para describir el enfoque del WRC, a la FLA se la ha llamado “amigable componedora”, “verificadora” o “colaboradora”. Por lo tanto, el principal dilema que crea una discordancia en estos dos enfoques es entre cobertura o rigor de la supervisión. En la Tabla 1, cada uno de estos dos aspectos ha recibido igual peso, recibiendo puntuación el WRC por rigor, pero no por cobertura sistemática, y la FLA recibiendo puntuación por cobertura, pero no por rigor (el WRC, no obstante, obtiene una mejor clasificación en transparencia y en participación de los trabajadores, lo que explica su mejor puntuación total). Sin embargo, al enfatizarse el contraste entre estos sistemas en esos términos, como ha sido común en los vehementes debates sobre los enfoques de la FLA y del WRC, se desvía la atención del hecho de que, desde el punto de vista de la protección efectiva de los derechos laborales, se necesitan tanto el rigor como la cobertura. En la práctica real de la supervisión, como se muestra posteriormente al examinar las campañas de sindicalización en Kukdong y Choishin, estos dos enfoques contrapuestos pueden desempeñar papeles complementarios en el cumplimiento de los estándares laborales.

\footnotetext{
${ }^{63}$ Morton Winston, "NGO Strategies for Promoting Corporate Social Responsibility.”

${ }^{64}$ Elliot y Freeman, “White Hats or Don Quixotes?”.

${ }^{65}$ O’Rourke, “Outsourcing Regulation.”
} 


\section{Tabla 1}

Comparación de sistemas de monitoreo por terceros

\begin{tabular}{|c|c|c|c|c|}
\hline & \multirow[t]{2}{*}{ WRC } & \multirow{2}{*}{ FL } & \multirow{2}{*}{$\begin{array}{c}\text { SAI } \\
(\text { SA8000) }\end{array}$} & \multirow[t]{2}{*}{ WRA } \\
\hline & & & & \\
\hline $\begin{array}{l}\text { ¿Libertad de asociación y negociación } \\
\text { colectiva? }\end{array}$ & Si & $\mathrm{Si}$ & Si & No \\
\hline ¿El trabajador puede presentar quejas? & Si & No & No & No \\
\hline $\begin{array}{l}\text { ¿La organización coordinadora es la } \\
\text { que elige y paga al monitor? }\end{array}$ & $\mathrm{Si}$ & $\mathrm{Si}$ & No & No \\
\hline ¿Los monitores son independientes? & $\mathrm{Si}$ & No & No & No \\
\hline ¿Las visitas son imprevistas? & $\mathrm{Si}$ & $\mathrm{Si}$ & $\mathrm{Si}$ & No \\
\hline ¿La supervisión es sistemática? & No & Si & No & No \\
\hline ¿La supervisión es continúa? & $\mathrm{Si}$ & No & No & No \\
\hline $\begin{array}{l}\text { ¿Los fabricantes deben revelar el } \\
\text { nombre y la localización de sus } \\
\text { suministradores? }\end{array}$ & $\mathrm{Si}$ & No & No & No \\
\hline $\begin{array}{l}\text { ¿La organización coordinadora } \\
\text { publica sus informes? }\end{array}$ & $\mathrm{Si}$ & $\mathrm{Si}$ & No & No \\
\hline $\begin{array}{l}\text { ¿La organización coordinadora tiene } \\
\text { capacidad sancionadora? }\end{array}$ & $\mathrm{Si}$ & $\mathrm{Si}$ & No & No \\
\hline Total & 9 & 6 & 2 & 0 \\
\hline
\end{tabular}

Fuente: Páginas en Internet de las propias organizaciones y MSN, "Codes Update”. WRC= Worker Rights Consortium. FLA= Fair Labor Association. SAI=Social Accountability Internacional. WRAP=Worlwide Responsable Apparel Production Certification Program. El código de la FLA incluye normas sobre presentación de quejas por los trabajadores, pero todavía no se han hecho cumplir de manera sistemática.

El primer informe de la FLA, que todavía se basa fuertemente en la información suministrada por las propias empresas, se publicó en el año 2003.

Sin perjuicio de la presencia de estas complicaciones, la Tabla 1 presenta claramente cuatro tendencias generales apoyadas por recientes estudios y por mi propia investigación etnográfica. Primero, los sistemas de verificación del cumplimiento de los códigos cuyo uso está más extendido (WRAP y SAI) son también los menos protectores y los que producen un menor empoderamiento de los trabajadores. En particular, el hecho de que el WRAP, una iniciativa de la asociación de fabricantes del vestido estadounidense, sea el programa preferido por las marcas estadounidenses cuya producción está dirigida a los grandes almacenes de descuento como Wal-Mart, significa que la mayoría del mercado del vestido 
sigue estando fuera del alcance de cualquier sistema serio de monitoreo del cumplimiento de los códigos. Segundo, las empresas de auditoría contratadas directamente por los supervisados predominan en la práctica del monitoreo. Por ejemplo, según el informe de la MSN del año 2003, “en el año 2000, Pricewaterhouse Coopers (a partir de la cual se creó posteriormente Global Social Compliance) llevó a cabo ella sola más de 2000 auditorías sociales”, ${ }^{66}$ Como nos ha mostrado O'Rourke, la supervisión de Global Social Compliance padece de algunos defectos fatales, como confiar en gran medida en los datos proporcionados por los administradores de las empresas, en las pruebas procedentes de visitas superficiales a las fábricas y en las entrevistas celebradas con los trabajadores bajo la supervisión de los administradores. ${ }^{67}$ Las empresas de auditoría son también dominantes en el sistema de supervisión de la FLA. Por ejemplo, de las 63 visitas de supervisión externas llevadas a cabo en las fábricas de Nike durante el año 2002-2003 usando el sistema de la FLA, virtualmente todas ellas fueron llevadas a cabo por empresas auditoras contratadas. ${ }^{68}$

En Guatemala y México, estas dos tendencias son percibidas por los trabajadores, líderes obreros y activistas protrabajador como importantes obstáculos para el cumplimiento efectivo de los códigos. Varios entrevistados señalaron que actualmente el monitoreo solo ve la “punta del iceberg”, al ocuparse únicamente de las fábricas orientadas a la exportación cuya producción va destinada a las marcas muy conocidas y al concentrarse en la violación aislada de los derechos individuales, más que en la promoción de los derechos colectivos. ${ }^{69}$ Como varios de estos actores han señalado, incluso evaluar consistentemente la punta del iceberg requeriría reemplazar a las empresas de auditoría privadas por auditores independientes. ${ }^{70}$ Se ha creado un pequeño grupo de auditores independientes pioneros, destacadamente COVERCO en Guatemala y el Grupo de Monitoreo Independiente (GMIES) en El Salvador, que podrían desempeñar ese papel. Sin embargo, como muestran los esfuerzos de COVERCO por conseguir marcas a las que auditar y por lograr que la FLA acepte las condiciones que ha establecido para garantizar la corrección y asegurar la credibilidad de sus informes (por ejemplo, el acceso continuo a las fábricas auditadas

\footnotetext{
${ }^{66}$ MSN, “Codes Update,” 17.

${ }^{67}$ O’Rourke, "Monitoring the Monitors.”

68 Fair Labor Association (FLA), "First Public Report: Towards Improving Workers' Lives” (www.fairlabor.org, 2003), 51.

${ }^{69}$ Entrevista con Arturo Alcalde; entrevista con el secretario general de FESTRAS; entrevista con Ken Kim (COVERCO), Ciudad de Guatemala, 2 de agosto de 2002

${ }^{70}$ Entrevista con Huberto Juárez (Universidad Autónoma de Puebla), Puebla, México, 8 de julio de 2002; entrevista con Luís Galicia (Avancso), Ciudad de Guatemala, 29 de julio de 2002.
} 
durante al menos seis meses y la posibilidad de publicar los informes), queda todavía un largo camino por recorrer antes de que el monitoreo independiente se convierta en la norma.

La tercera tendencia sugerida por la Tabla 1 es más esperanzadora para la causa de la protección de los derechos de los trabajadores y del empoderamiento obrero. Aunque todavía es incipiente, algunos experimentos en la verificación del cumplimiento de los códigos, especialmente el del WRC, pero también el de la FLA en los casos recientes de Choishin y BJ\&B, se han movido en la dirección de la RELAPET. Dos características esenciales del sistema del WRC han atraído a los trabajadores y fortalecido gradualmente su componente participativo. Primero, el WRC ha trabajado con las ONG y las organizaciones obreras locales en equipos conjuntos de investigación. Esta práctica fue primero puesta a prueba en el caso de Kukdong y practicada con éxito en tiempos más recientes en el caso de la fábrica de BJ\&B en República Dominicana, un contratista de Nike que fabrica gorras con el emblema de las universidades estadounidenses. Este caso supuso un esfuerzo de colaboración entre la FLA y el WRC que culminó con la formación de un sindicato independiente y la firma de un convenio colectivo en marzo de $2003 .{ }^{71}$ También, al trabajar en colaboración con activistas locales a favor de los trabajadores, el WRC ha ayudado a construir la capacidad de las organizaciones de apoyo a los trabajadores que están teniendo un importante papel autónomo en la organización de campañas y en el fomento de la vigilancia efectiva. La colaboración entre el WRC y el Centro de Apoyo al Trabajador (CAT) en México, una organización que tuvo un papel central en las negociaciones de Kukdong, es otro ejemplo apropiado. La importancia de las organizaciones de apoyo a los trabajadores no puede destacarse lo suficiente. De hecho, son los principales participantes en las RATN y tienen un papel fundamental en las comunidades locales. Muchas de ellas, como Factor X, en Tijuana (México); el Centro de Orientación de la Mujer Obrera (COMO), en Ciudad Juárez (México) y La Mujer Obrera, en El Paso (Texas), son organizaciones feministas independientes, pero que trabajan en colaboración con los sindicatos. ${ }^{72}$ En segundo lugar, el WRC ha involucrado también a los trabajadores individualmente al establecer programas de educación populares y de

\footnotetext{
${ }^{71}$ David Gonzalez, “Latin Sweatshops Pressed by U.S. Campus Power,” The New York Times (4 de abril de 2003).

${ }^{72}$ Thalia Kidder, "Networks in Transnational Labor Organizing," en S. Khagram, J. Riker, y K. Sikkink, eds., Restructuring World Politics: Transnational Social Movements, Networks and Norms (Minneapolis: University of Minnesota Press, 2002): 269-93.
} 
formación, y crear mecanismos para canalizar las quejas directamente presentadas por ellos. Es interesante observar que la SAI también se ha movido en esta dirección en los últimos años, al colaborar con el sindicato global de la industria del vestido, la International Textile, Garment and Leather Workers Federations (ITGLWF), en un programa de formación para los trabajadores en diferentes partes del mundo. ${ }^{73}$ Estos esfuerzos intentan paliar un defecto fundamental de los sistemas de monitoreo existentes que se hace evidente durante las entrevistas y las visitas a las fábricas. La gran mayoría de los trabajadores simplemente no conoce la existencia de los códigos de conducta, y mucho menos los mecanismos que pueden usar para hacerlos efectivos. Por ejemplo, los líderes sindicales en Kukdong y Choishin describieron como los trabajadores generalmente asociaban el término “código de conducta” con normas acerca de cual era el comportamiento que la empresa esperaba de ellos. Incluso los abogados laboralistas, los propietarios de las fábricas y los activistas de las ONG, exceptuando aquellos involucrados en el monitoreo de las fábricas, saben muy poco acerca de los códigos de conducta.

Sin embargo, esta posición proactiva ha hecho mucho más difícil al WRC poder obtener la cooperación de las empresas que monitorea. También, el alcance limitado de la vigilancia del WRC implica que la mayoría de las fábricas no estén cubiertas por el sistema de monitoreo. Por estas razones, una tendencia igualmente alentadora, la cuarta que refleja la Tabla 1, es el “efecto estimulante” recíproco que tienen los sistemas del WRC y de la FLA. Mientras que la alta credibilidad del WRC ha forzado a la FLA a realizar cambios sustantivos en sus normas, principalmente haciendo que ella misma escoja y pague directamente a los auditores en lugar de que lo hagan las empresas miembros y haciendo esfuerzos preliminares por aumentar la transparencia de sus prácticas de vigilancia y control, la cooperación entre delegados de ambas organizaciones en equipos conjuntos de investigación (especialmente en el caso BJ\&B) ha creado una mezcla entre el marco cognitivo y la estrategia adversarial a favor de los trabajadores que caracteriza al WRC, y la estrategia y el marco favorable a la colaboración con las empresas de la FLA. Por lo tanto, desde el punto de vista de la protección efectiva de los derechos laborales a través de los códigos de conducta, la coexistencia de sistemas antagonistas, como el del WRC, y de sistemas de colaboración, como el de la FLA, es más un activo que un pasivo. Como nos ha mostrado Elliot y Freeman, la estrategia óptima para que prosperen conjuntamente los fines

\footnotetext{
${ }^{73}$ Kearney y Gearhart, "Workplace Codes as Tools for Workers.”
} 
gemelos del rigor y la cobertura en la supervisión es algún tipo de combinación de antagonismo (que pueda poner una presión continua sobre las ET y sus suministradores para que cumplan con los códigos) y de colaboración (para promover la difusión de estándares laborales más altos a lo largo de toda la cadena global de producción de bienes). ${ }^{74}$

Recientes estudios de las tendencias en vigilancia y control a lo largo de todo el mundo corroboran la imagen ambivalente que surge de mi investigación y apoyan el caso favorable al desarrollo de mecanismos institucionales incipientes que reflejen el enfoque de la RELAPET. Aunque el informe de la MSN del año 2004 señala la falta de una masa crítica de marcas comerciales comprometidas con un monitoreo riguroso y también el predominio insistente de la contratación directa de empresas de auditoría, recoge al mismo tiempo el descontento creciente que tienen los sindicatos, las ONG que apoyan los derechos de los trabajadores y algunas marcas comerciales con un modelo de supervisión limitado al “control de políticas” o a la verificación de una "lista de obligaciones”. El informe de la MSN da cuenta también de la mayor experimentación con enfoques participativos que conceden un mayor empoderamiento a los trabajadores y a la colaboración entre los sistemas más rigurosos de supervisión. ${ }^{75}$ Algunos de los mecanismos específicos institucionales documentados en estos estudios que conducirían hacia el modelo de la RELAPET son la proliferación de derechos laborales (iniciativas de formación laboral, participación de los trabajadores y de la sociedad civil en el monitoreo, promoción de la representación de los trabajadores en órganos tales como los comités de salud y seguridad ocupacional) y los esfuerzos incipientes por garantizar efectivamente el derecho a la negociación colectiva en las fábricas globales.

En resumen, la experimentación con nuevos esquemas institucionales que facilitan la entrada de voces divergentes (especialmente las de los trabajadores y las organizaciones obreras locales) nos muestra ya el potencial de la RELAPET. Por lo tanto, no es ninguna sorpresa que los dos primeros convenios laborales colectivos firmados en las fábricas globales latinoamericanas (Kukdong y BJ\&B) cuya producción está destinada a marcas comerciales que han adoptado códigos de conducta, hayan sido el producto de las

\footnotetext{
${ }_{75}^{74}$ Elliot y Freeman, Can Labor Standards Improve Under Globalization?, 50, 64.

75 MSN, "2003 Year End Review: Emerging Trends in Codes and Their Implementation," (www.maquilasolidarity.org, 2004). Un estudio del Banco Mundial en Honduras, Kenia, China, e India llegó a una conclusión parecida; véase World Bank, "Strengthening the Implementation of Corporate Social Responsibility in Global Supply Chains,” (octubre 2003).
} 
investigaciones participativas promovidas por el WRC, y que en el caso más reciente, Choishin, estuviera involucrada una organización, la FLA, que se ha sentido presionada para moverse en esta dirección. Como ya se ha argumentado, junto con esquemas institucionales propicios, la movilización política efectiva es un componente central de la RELAPET. A la luz de la resistencia continua por parte de la mayoría de las marcas comerciales, los proveedores y las organizaciones coordinadoras del monitoreo a la creación de las condiciones que permitan exigir siquiera el cumplimiento de los derechos individuales más básicos, conseguir vincular los sistemas de monitoreo a procesos de mejora constantes con el propósito de que atiendan el problema del empoderamiento de los trabajadores depende en última instancia de la eficacia del contrapoder que puedan ejercer las redes antimaquila transfronterizas, los Estados nacionales y las organizaciones internacionales bajo la presión de estas redes. Teniendo en cuenta las profundas diferencias de poder entre actores en la cadena global de producción del vestido, esa presión externa se necesita para establecer las condiciones políticas que permitan que las organizaciones obreras y de apoyo a los trabajadores se impliquen en una vigilancia de los estándares laborales consistente con la propuesta de la RELAPET. En la siguiente sección dejo el esquema institucional y paso a la cuestión estrechamente relacionada, pero analíticamente distinta, de la movilización política, y para ello documento el uso de los códigos por las RATN que apoyan la sindicalización de los trabajadores en Kukdong y Choishin.

\section{Códigos de conducta y estrategias políticas}

El 9 de enero de 2001, más de 600 de los 850 trabajadores de Kukdong International, por entonces un contratista de Nike y Reebok, ocuparon el patio de la fábrica. Tenían tres reivindicaciones: la comida de la cafetería debía mejorar, ya que a menudo estaba podrida y llena de gusanos; el sindicato corrupto, apoyado por la empresa, debía reemplazarse por un sindicato independiente creado por los trabajadores; y la empresa debía reintegrar a los cinco supervisores que fueron despedidos por ayudar a organizar un boicot a la cafetería unas cuantas semanas antes. ${ }^{76}$ La administración de la empresa se negó a negociar. En lugar de ello, presentó una denuncia en los tribunales penales contra los trabajadores, que fueron rápidamente procesados. Para evitar un “daño mayor a la propiedad privada”, la policía

\footnotetext{
${ }^{76}$ Tal y como recuerda Marco Santiago Pérez, uno de los líderes de la campaña, en Centro de Apoyo al Trabajador, “La Lucha Sigue: Stories from the People of the Kukdong Factory” (Puebla: CAT, 2001).
} 
invadió la fábrica en la noche del 11 de enero. Mientras se oían los gritos de los aterrorizados padres que habían ido a la fábrica a llevarles comida y ropa a sus hijos, cerca de 400 trabajadores jóvenes, casi todos ellos menores de edad o en torno a los 20 años, fueron violentamente desalojados de la fábrica. Hubo que hospitalizar a tres trabajadores y al menos 30 trabajadores resultaron heridos. El 13 de enero se reinició la producción en la fábrica, pero la administración de la empresa no permitió que varios de los trabajadores volvieran al trabajo en represalia por su liderazgo durante el paro obrero. Muchos otros trabajadores no volvieron a la fábrica por el temor a ser golpeados nuevamente. Cuando visité sus casas en marzo de ese año, sus padres, llorando, seguían negándose a dejarles regresar al lugar en el que habían sido golpeados brutalmente, a pesar de las garantías de otros trabajadores y de los organizadores.

Con el fin de la huelga, parecía haberse restaurado el status quo en la fábrica del vestido más emblemática del estado de Puebla, el estado mexicano presentado como la vanguardia de la “revolución de la maquila” que barría México y Centroamérica. Un periódico local citó la afirmación de los administradores de Kukdong de que no había pasado nada y que las cosas habían vuelto a la normalidad. ${ }^{77}$ Por una vez, sin embargo, las cosas no volvieron a la normalidad. Nueve meses después, el 8 de octubre, The New York Times informaba sobre la firma del primer convenio colectivo entre un sindicato independiente y una fábrica del vestido en México. ${ }^{78}$ La fábrica era Kukdong y los trabajadores eran los mismos que habían participado valientemente en la huelga. Lo que representó la diferencia fue la cadena de protestas y negociaciones en México y EE.UU. entre esas dos fechas. Lo más importante para nuestros propósitos es que en esas protestas y negociaciones una RATN, que comprendía un amplio conjunto de actores locales e internacionales (véase Tabla 2), y que recurrió a la estrategia política de hacer a la empresa responsable ante la sociedad, le dio un uso fundamental a los códigos de conducta de Nike y Reebok y a los sistemas de monitoreo.

Las cosas no fueron tan bien para los casi 1100 trabajadores de Choishin, el complejo de maquiladoras compuesto por dos fábricas que se encuentra en medio de una región de volcanes y pueblos pobres a las afueras de Ciudad de Guatemala. Las condiciones laborales en la fábrica no eran diferentes a aquellas en Kukdong y en el sector de la maquila en general. Horas extraordinarias obligatorias, bajos salarios, y el abuso físico y verbal contra

\footnotetext{
${ }^{77}$ Diario Síntesis (13 de enero de 2001).

${ }^{78}$ Ginger Thompson, “Mexican Labor Protest Gets Results,” The New York Times (8 de octubre de 2001).
} 
la fuerza de trabajo, mujeres en su mayor parte, se habían convertido en la norma. ${ }^{79}$ Tras dos años de organización clandestina, el 9 de julio de 2001 un grupo de 20 trabajadores presentaron al gobierno una solicitud oficial para que se reconociera su sindicato recientemente creado. La respuesta de la administración de la empresa ejemplifica decididamente los obstáculos ya mencionados que enfrentan los sindicatos en el sector del vestido en Guatemala. Según el informe de COVERCO, la ONG independiente que había verificado el cumplimiento de la fábrica con el código de conducta de Liz Claiborne, el mismo día en que los trabajadores solicitaron el reconocimiento oficial del sindicato, un grupo de abogados contratados por la asociación guatemalteca de fabricantes del vestido, VESTEX, visitó la fábrica para disuadir a los trabajadores de que se afiliaran al sindicato y los invito a unirse a una asociación "solidaria” que pretendía anticiparse y prevenir la formación del sindicato. ${ }^{80}$ Los administradores incitaron también a los supervisores de la fábrica a que extendieran el rumor de que la existencia de un sindicato llevaría al cierre de la misma.

Poco tiempo después la situación se tornó violenta, en hechos que nos recuerdan todas las características de la historia reciente de Guatemala. El 18 de julio, trabajadores con palos y cadenas rodearon a los líderes que impulsaron clandestinamente la creación del sindicato. ${ }^{81}$ En una escena que, según los trabajadores y los monitores independientes de COVERCO, recordaba a los linchamientos que han plagado las zonas rurales guatemaltecas desde los peores años de la guerra civil, los trabajadores antisindicalistas golpearon a los líderes sindicales y les amenazaron con rociarles de gasolina y prenderles fuego. Bajo semejante presión, algunos de los líderes firmaron cartas de renuncia en blanco y fueron rápidamente despedidos por la administración de la empresa. Otros se negaron a firmar y consiguieron escapar de las instalaciones de la fábrica. Durante todos estos hechos, los trabajadores antisindicalistas tuvieron el apoyo pasivo o activo de la administración de la empresa, que alegaba que no tenía ningún control de la situación. ${ }^{82}$

Unos cuantos días después, con posterioridad a que el representante de Liz Claiborne en Guatemala y COVERCO intervinieran para detener la violencia, se permitió a los líderes

\footnotetext{
${ }^{79}$ Entrevista colectiva con líderes del sindicato de Choishin, Ciudad de Guatemala, 5 de agosto de 2002.

${ }^{80}$ COVERCO, "Un informe especial de COVERCO: El Código de Conducta de Liz Claiborne Inc. y la sindicalización de dos fábricas proveedoras en Guatemala,” (www.coverco.org, 2001).

${ }^{81}$ Entrevista colectiva con líderes de los sindicatos textiles de Choishin/Cima. Ciudad de Guatemala, 5 de agosto de 2002; entrevista con el secretario general de FESTRAS.

${ }^{82}$ Entrevista colectiva con líderes sindicales de Choishin/Cimatextiles; entrevista con el secretario general de FESTRAS. Véase también COVERCO, "Un Informe Especial.”
} 
sindicales volver al trabajo, y los funcionarios laborales de la administración estatal autorizaron la creación del sindicato, el primero en el sector del vestido guatemalteco. Durante dos años, sin embargo, el sindicato estuvo siempre al borde de la disolución. No creció nunca más allá de su pequeña afiliación original y, por lo tanto, no pudo firmar ningún convenio colectivo. En el momento en que realicé el trabajo de campo (agosto de 2002), los trabajadores se encontraban desilusionados y la administración veía el sindicato como una mera molestia que estaba totalmente bajo control. Por ello, tuvo que ocurrir un hecho inesperado para que revivieran la RATN y el sindicato. El 3 de junio de 2003, el ministerio del trabajo guatemalteco anunció el cierre de Choishin por "violaciones al derecho laboral”. El anuncio del gobierno pretendía presionar a Choishin para que negociara un contrato con el sindicato y pusiera con ello fin al problema, cuya visibilidad internacional se había convertido en un obstáculo para la participación de Guatemala en el Tratado de Libre Comercio entre Centroamérica y EE.UU. (CAFTA, por sus siglas en inglés), que se firmó finalmente en diciembre de $2003 .^{83}$ El anuncio incentivó una intensa ronda de negociaciones en la que participaron numerosos actores nacionales e internacionales, y que culminó con la firma de un convenio colectivo el 9 de julio y la decisión del gobierno guatemalteco, el 16 de julio, de aceptar el convenio y cesar la amenaza de sanciones contra Choisin. ${ }^{84}$

La lista de la Tabla 2 recoge a los actores que participaron en los dos casos y resume el papel de cada uno de ellos en la firma de los contratos colectivos.

\footnotetext{
${ }^{83}$ US/LEAP, “The Guatemala Surprise,” (www.uELCMap.org., 2003).

${ }^{84}$ Entrevista telefónica con el líder sindical de Choishin, 17 de julio de 2003.
} 
Tabla 2

Actores en los casos de Kukdong y Choishin

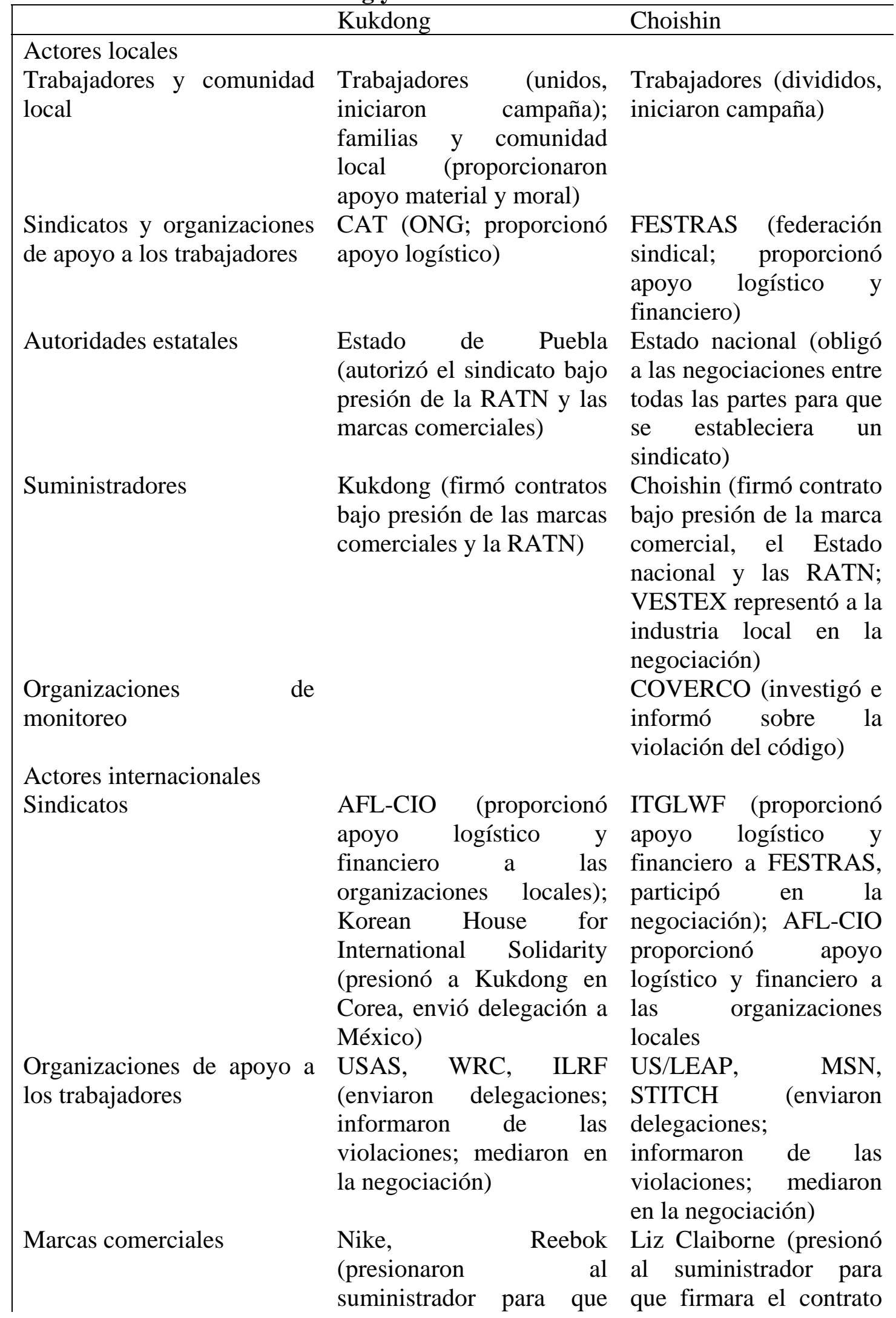




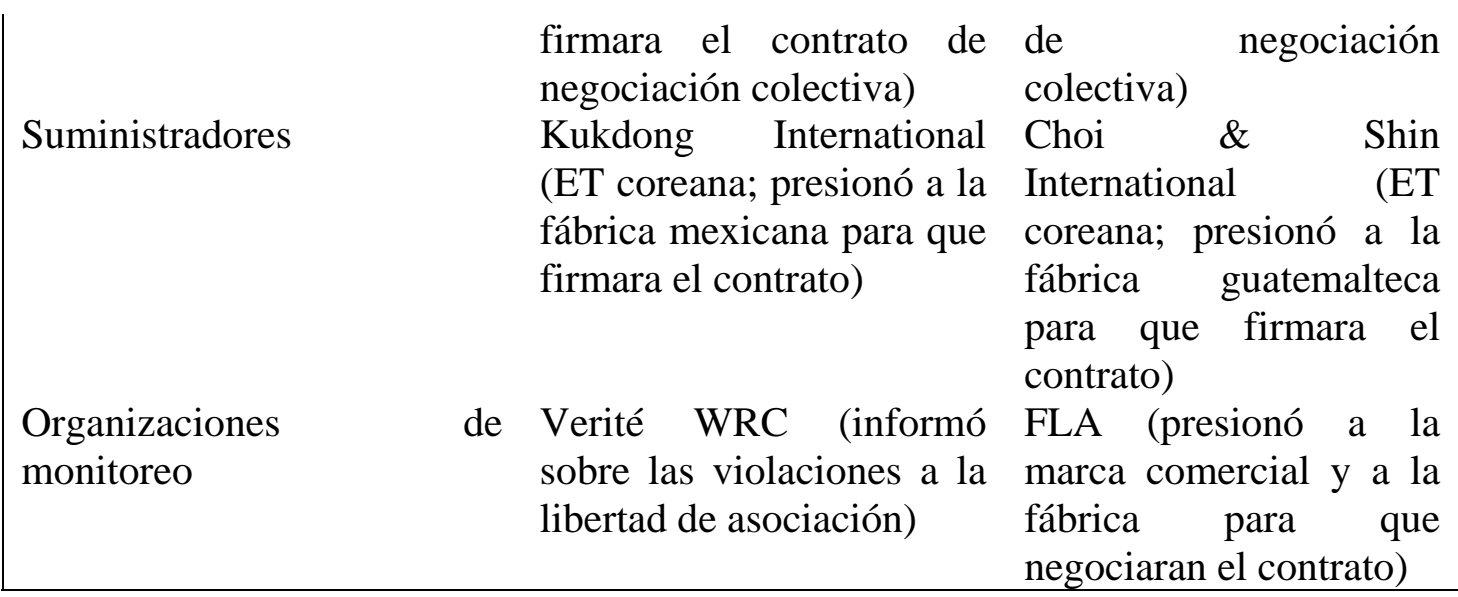

Nota: CAT=Centro de Apoyo al Trabajador; FESTRAS=Federación Sindical de Trabajadores de Alimentación, Agroindustrias y Similares; RATN=Redes de Activismo Transnacionales; VESTEX=Comisión de Vestuario y Textiles; COVERCO=Commission for the Verification of Codes of Conduct; ITGLWF=International Textile, Garment and Leather Worker Federation; AFL-CIO=American Federation of Labor-Congress of International Organization; US/LEAP=US/Labor Education in the Americas Project; MSN=Maquila Solidarity Network; WRC=Worker Rights Consortium; STITCH= Support Team International for Textileras; FLA=Fair Labor Asociation.

¿Qué explican los resultados de estos dos casos? ¿Qué es lo que diferencia estas campañas transfronterizas de movilización de la multitud de campañas que han fracasado a la hora de crear sindicatos independientes? Una respuesta sistemática a estas preguntas requeriría un examen detallado de las características de los actores participantes, la vulnerabilidad relativa de las marcas comerciales y de los suministradores objeto de las acciones de protesta, y del modelo de movilización transfronteriza en cada caso, al igual que una comparación con los casos no exitosos. A la vista de los propósitos analíticos específicos de este artículo, no emprenderé una comparación detallada aquí. En lugar de ello, me concentraré en el efecto producido por uno solo de los factores en los excepcionales resultados de los casos de Kukdong y Choishin, como es el uso de los códigos y de las instituciones de monitoreo por los actores de las RATN. La atención central que le presto a esa característica pretende descubrir las posibilidades no realizadas para el cumplimiento de los estándares laborales internacionales y también proporcionar una base empírica para el enfoque de la RELAPET a los códigos de conducta que pueda contribuir a la realización de esas posibilidades. En la última sección, ampliaré el estudio de este potencial conectando las lecciones que pueden extraerse de los dos casos con otros progresos prometedores en el monitoreo de los códigos de conducta en diversas partes del mundo. 
Como afirman Keck y Sikkink, un factor clave para mejorar el impacto de las RATN es la posibilidad de usar procedimientos y normas institucionalizadas que hayan sido aceptadas por los actores contra los cuales se dirige la protesta. Una vez que las ET, los Estados y los actores objeto de la protesta se han comprometido públicamente con cambiar su posición y cumplir con un conjunto de normas o principios (en los casos aquí estudiados, relativos a la protección de los derechos laborales en las fábricas globales), las coaliciones pueden usar estrategias políticas dirigidas a exigirles a las empresas que respondan por su conducta ante la sociedad para hacer que estos actores cumplan con sus normas o principios reconocidos. ${ }^{85}$ El potencial de este tipo de política como fuente de contrapoder reside en el hecho de que puede explotar la distancia existente entre el discurso y la práctica para avergonzar a los actores contra los que se dirige la protesta por no mantener su palabra. Cuando los actores contra los que se dirige la protesta dependen fuertemente de su imagen, como ocurre con marcas comerciales globales como Nike, Reebok y Liz Claiborne, la política de la vergüenza puede ser tremendamente efectiva. En estos casos, como lo ha señalado Naomi Klein, "la marca, la imagen de marca, la fuente de tanta riqueza corporativa, termina también por ser el talón de Aquiles corporativo". 86

Las estrategias políticas dirigidas a exigirles a las empresas responsabilidad ante la sociedad funcionan mejor cuando los actores contra los que se dirige la protesta se han comprometido a respetar reglas y procedimientos precisos para su cumplimiento, en vez de principios vagos con débiles mecanismos de cumplimiento. Ahí reside el potencial de los códigos rigurosos de conducta y de los esquemas de supervisión efectivos para facilitar la entrada de las voces discrepantes y compensadoras de los trabajadores y de las organizaciones de apoyo a los trabajadores locales en cooperación con las RATN. Sin importar cuan reluctantes sean las marcas globales a firmar los códigos de conducta y sistemas de monitoreo, una vez que lo han hecho quedan expuestas a las estrategias políticas que les exigen responder socialmente por sus actos, lo cual crea una oportunidad mayor para la movilización transfronteriza y la organización obrera. Sistemas de monitoreo que supongan un compromiso inequívoco con los derechos colectivos y con facilitar la participación de voces discrepantes, como la de los trabajadores, las ONG locales y los consumidores organizados del sistema del WRC, expanden todavía más la oportunidad de movilización entre trabajadores de distintos países. Pero incluso en sistemas que se basan

\footnotetext{
${ }^{85}$ Keck y Sikkink, Activists Beyond Borders, 24-5.

${ }^{86}$ Naomi Klein, No Logo (Nueva York: Picador, 2000), 343.
} 
más en la colaboración con las empresas y que dan un empoderamiento menor a los trabajadores, como el de la FLA, mecanismos tales como el uso de monitores independientes (frente al de empresas de auditoría contratadas por las propias empresas o sus asociaciones empresariales), cuando se combinan con la presión de las RATN, pueden facilitar la aparición de organizaciones obreras con poder real, como nos muestra el caso del sindicato de Choishin.

De esta forma, los códigos de conducta pueden contribuir a la aparición de lo que Collins ha llamado "nuevas comunidades internacionales que vigilan la responsabilidad social” y que representarían una esfera pública global incipiente capaz de vigilar el poder de las ET y de proporcionar las condiciones de fondo y la influencia política requeridas para que los trabajadores locales y las organizaciones de apoyo a los trabajadores puedan participar trascendentalmente en la gobernanza de las relaciones laborales. ${ }^{87}$ La Tabla 2 presenta esa combinación entre presión externa y empoderamiento local que es esencial para el enfoque de la RELAPET en relación con el cumplimiento de los códigos. La aparición de sindicatos en Kukdong y Choishin es el resultado del efecto conjunto de la presión internacional sobre las marcas y sus suministradores por parte de Estados Unidos, Corea y los sindicatos y ONG globales, junto con procesos locales de deliberación y negociación en los que participaron los sindicatos guatemaltecos y mexicanos, las organizaciones de apoyo a los trabajadores y las autoridades estatales, junto con actores internacionales que enviaron a sus representantes a las fábricas para mediar directamente en la negociación. Sin la presión internacional no hubieran podido lograrse las condiciones políticas necesarias para superar la resistencia arraigada de las marcas comerciales, de los suministradores locales, de las asociaciones empresariales y de las autoridades del Estado. Sin el esfuerzo local, el difícil proceso (y en el caso de Choisin, interrumpido y luego retomado) de organización obrera no hubiera llevado a la formación de un sindicato y a la firma de un convenio colectivo de trabajo. El proceso y el resultado de las dos campañas, a su vez, expandió más las posibilidades de participación políticamente consciente de los trabajadores en el cumplimiento de los códigos, puesto que los sindicatos recientemente creados y los actores locales preexistentes que participaron en cada uno de los casos adquirieron una capacidad nueva o mejorada para influenciar en la vigilancia y el control de

\footnotetext{
87 Jane Collins, Threads: Gender, Labor and Power in the Global Apparel Industry (Chicago: Chicago University Press, 2003), 190; véase también Fung, "Deliberative Democracy and International Labor Standards," 67-8.
} 
los códigos con el apoyo de los actores internacionales, con los cuales establecieron vínculos estrechos durante las campañas. Finalmente, otro elemento evidente en la Tabla 2, que estaría presente en una perspectiva que encarnase la RELAPET para el monitoreo de las condiciones de trabajo, es el papel esencial desempeñado por los monitores independientes (COVERCO en Choishin y Verité en Kukdong) en colaboración con las organizaciones coordinadoras de monitoreo (el FLA y el WRC respectivamente). Ambos impulsaron decisivamente las negociaciones que culminaron en el establecimiento de los sindicatos.

Esta combinación de presión externa y de diálogo local se pudo ver vívidamente en la combinación de actores que participaron en la intensa ronda de negociaciones que condujo a la firma del contrato en Choishin. A las cuatro reuniones organizadas por el gobierno en Ciudad de Guatemala acudieron el ministro de economía, el ministro de trabajo, un representante de la embajada coreana en Guatemala, el presidente de Choi \& Shin International (la ET coreana dueña de la fábrica), los representantes sindicales, el secretario general de FESTRAS, el secretario general de la ITGLWF, un representante de US/LEAP (una ONG transnacional activista), un delegado de COVERCO, el director de contratación externa de Liz Claiborne, un experto laboral de VESTEX y el director de la FLA. ${ }^{88}$ Igualmente, las reuniones de febrero de 2001 que produjeron el reintegro de los líderes del paro laboral en Kukdong y abrieron el camino a la formación de un sindicato independiente, supusieron la participación de actores nacionales e internacionales, en este caso un académico mexicano a favor de los trabajadores en representación de Reebok, tres directores coreanos de la empresa Kukdong, un representante de Nike y un delegado de FROC-CROC (la federación sindical corrupta a la cual el sindicato empresarial de la fábrica estaba afiliado). Es bastante representativo que la tarea de coordinar la reuniones y de traducir del español al coreano y viceversa se realizara por un delegado de la Korean House for International Solidarity (KHIS), una ONG de origen coreano que pretende que las compañías coreanas sean responsable socialmente por sus prácticas laborales en todo el mundo. Como en los otros casos, la KHIS presionó a la empresa tanto en Corea como en el país de producción al hacer público el caso en el Congreso y en los medios de comunicación coreanos y enviando una delegación a México.

\footnotetext{
${ }^{88}$ Entrevista telefónica con el líder sindical de Choishin, 17 de julio de 2003.
} 
El potencial de los códigos de conducta para generar estos efectos era claro para todos los miembros de las campañas de movilización de Kukdong y Choishin. Al elegir estas fábricas como objetivos, el hecho de que las factorías produjeran para marcas comerciales que eran parte de sistemas de monitoreo y, por consiguiente, sensibles a las estrategias políticas dirigidas a exigirles cumplir con su responsabilidad social, tuvo mucha influencia en las mentes de los organizadores. ${ }^{89}$ En el caso de Kukdong, Nike y Reebok, presionadas por una RATN que estaba usando estrategias políticas dirigidas a exigirles esa responsabilidad, dichas tácticas tuvieron un papel importante a la hora de conseguir que la fábrica suministradora permitiese la formación de un sindicato independiente y firmará un convenio colectivo. Al comentar la campaña de Kukdong, el director del AFL-CIO Solidarity Center describe muy bien las oportunidades y las tensiones intrínsecas al uso de los códigos de conducta para organizar protestas:

Nike y Reebok tuvieron un papel instrumental para que se llegara una solución final positiva en Kukdong. Probablemente no lo hicieron por razones altruistas, pero eso no importa, son empresas. Promulgaron los códigos porque se resintieron debido a la presión de los estudiantes y también de la administración Clinton en alguna medida... así que piensan que tener un código y que sea vinculante es en su interés. Fue por ello, porque veían que era conforme a su propio interés que sus suministradores cumplieran y respetaran realmente las condiciones establecidas en los códigos, que cuando fueron conscientes de que esas condiciones no se respetaban, pusieron un montón de presión sobre sus suministradores. Así, las empresas se convirtieron efectivamente en aliadas; bueno, no quiero decir que fueran aliadas naturales u orgánicas de los trabajadores... pero a efectos prácticos eran sus aliadas. ${ }^{90}$

Igualmente, el hecho de que Liz Claiborne hubiera firmado el código de conducta de la FLA y contratado una ONG independiente (COVERCO) para supervisar las condiciones de trabajo en Choishin creó una oportunidad que fue aprovechada por la RATN que apoyaba la formación del sindicato. Teniendo en cuenta el compromiso del código de la FLA con la libertad de asociación y la presencia de COVERCO en la factoría para dar testimonio de las violaciones al mismo, Liz Claiborne sufría una presión adicional para detener las formas más abiertas de actividades antisindicales, especialmente la violencia contra los líderes sindicales. El representante de Liz Claiborne en Guatemala intervino rápidamente para

\footnotetext{
${ }^{89}$ Entrevista con Blanca Velásquez y David Alvarado (CAT), Atlixco, México, 10 de julio de 2002; entrevista con el secretario general de FESTRAS.

${ }^{90}$ Entrevista con el Director de programas del Solidarity Center for the Americas de AFL-CIO, Dallas, 28 de marzo de 2003.
} 
poner fin a la violencia y amenazó con terminar las relaciones de negocios con la fábrica a menos que la administración de la empresa controlase a los grupos antisindicales.

Sin embargo, como he afirmado anteriormente, los distintos sistemas de monitoreo crean oportunidades diferentes para el ejercicio de un contrapoder y de la movilización obrera. Los mecanismos incorporados dentro del sistema del WRC para presionar a los actores contra los cuales iban dirigidas las protestas y mantener esa presión a lo largo del tiempo producían un contexto institucional más propicio para el éxito del sindicato en Kukdong que el que ofrecían los mecanismos de la FLA en el caso de Choishin. Mientras que los trabajadores de Kukdong podían contar con la movilización de los consumidores (los estudiantes universitarios estadounidenses organizados por USAS), representados eficazmente en la organización coordinadora de monitoreo (el WRC) para mantener la presión más allá de la huelga y las negociaciones iniciales, el hecho de que la organización coordinadora de monitoreo, que en el caso de Choishin era la FLA, estableciera condiciones menos rigurosas para sus empresas miembros, junto con el hecho de que no implicaba una presión continua de los consumidores organizados, significó que la oportunidad inicial para la formación del sindicato no pudiera mantenerse y expandirse de tal manera que el sindicato incrementase su afiliación y consiguiera que se firmara un convenio colectivo. Ausente la presión institucionalizada y constante, los administradores de la empresa en Choishin recurrieron a estrategias más sutiles, pero igualmente efectivas, de conducta antisindical, permitiendo simultáneamente a Liz Claiborne afirmar que cumplía plenamente con su código de conducta. Fue sólo durante las negociaciones de junio-julio de 2003 que la FLA adoptó finalmente una posición proactiva frente a la resistencia de Liz Claiborne y de la administración de la empresa a garantizar el derecho a la negociación colectiva. La FLA, al amenazar con pedirle al resto de marcas comerciales afiliadas que no contrataran con Choi \& Shin International si se cerraba y relocalizaba la fábrica, redujo la viabilidad de la opción de abandonar el mercado local para la empresa.

Por último, ¿̇la existencia de sindicatos ha supuesto una diferencia en términos de las condiciones laborales en las fábricas? El argumento a favor de concentrarse en los derechos colectivos mediante el enfoque a los códigos de conducta que proporciona la RELAPET lleva aparejado, no sólo los beneficios que derivan del empoderamiento obrero en sí mismo, sino también, y de manera fundamental, el potencial para producir mejoras sostenibles de los derechos individuales. En consecuencia, la larga vida del sindicato de 
Kukdong nos proporciona una prueba más adecuada acerca de este asunto esencial. Las condiciones de trabajo en la fábrica mejoraron impresionantemente después de la firma del convenio colectivo. El convenio aprobó un aumento salarial del 40 por ciento, el cual, aunque sigue siendo insuficiente, sitúa los salarios en un nivel considerablemente mejor que el del promedio de la industria. ${ }^{91}$ Durante la visita a la fábrica fueron evidentes las inversiones a largo plazo que contribuyen a los cambios sostenibles en las condiciones laborales. Se construyó una nueva cafetería y se instaló costoso equipo en las áreas de costura para mejorar las condiciones de salud y seguridad en el trabajo. ${ }^{92}$ En coordinación con Nike y el sindicato, la administración de la empresa ha tomado varios pasos para mejorar la conciencia de los trabajadores en relación a sus derechos según el código y el derecho laboral mexicano. La primera cosa que llama la atención del visitante al entrar en la fábrica es un afiche enmarcado que contiene el código de conducta de Nike. Etiquetas adhesivas con el texto del código de conducta se encuentran pegadas a cada máquina de coser. También es importante destacar que el supervisor en cada línea de trabajo es un miembro del sindicato, y que los representantes sindicales participan durante la formación sobre derechos laborales que se les da los nuevos trabajadores. Estos cambios han reducido el temor y el sentido de inseguridad entre los trabajadores y les han permitido, por lo tanto, organizarse mejor para impulsar mejoras continuas en los salarios y las condiciones laborales en la fábrica. ${ }^{93}$ Aunque es demasiado pronto para determinar si el sindicato en Choishin ha tenido un impacto duradero en los derechos individuales, ya hay pruebas de que se ha convertido en un mecanismo eficaz para dar curso a quejas individuales de los trabajadores que de otra forma no hubieran sido atendidas. Frente a las prácticas existentes en la fábrica que violan los estándares legales y de los códigos sobre retribución por horas extras, beneficios y pagos por despidos, el sindicato ha proporcionado a los trabajadores el apoyo necesario para conseguir que la administración de la empresa se ocupe de las infracciones sobre la base de los casos individuales. También, en cumplimiento de los términos del convenio colectivo, se han construido las instalaciones para una guardería infantil, se ha establecido una oficina sindical y un tablero informativo. ${ }^{94}$ Que estas mejoras duren a la vista de las continuas estrategias antisindicales por parte de la administración es algo que todavía está por verse.

\footnotetext{
${ }^{91}$ Entrevista con el Director de programas del AFL-CIO’s Solidarity Center for the Americas.

${ }^{92}$ Visita a Kukdong y entrevista con los administradores de la empresa, Atlixco, 11 de julio de 2002.

${ }^{93}$ Entrevista colectiva con los líderes sindicales de Kukdong, Atlixco, 12 de julio de 2002.

${ }^{94}$ Entrevista telefónica con el abogado del sindicato de Choishin, 5 de abril de 2004.
} 


\section{Conclusiones}

El examen empírico de los códigos en acción expone los riesgos de que el modelo de la gobernanza fracase como producto de las diferencias de poder. Al concentrarse intensivamente en los éxitos de las redes de colaboración y en sus perspectivas para una mejor eficiencia económica y legitimidad política, las teorías dominantes sobre gobernanza han pasado mayormente de largo sobre esta cuestión. Como nos muestra la realidad de los esquemas de vigilancia y control de los códigos de conducta empresariales orientados hacia los intereses de las compañías, si no existe un contrapoder los sistemas para la gobernanza pueden convertirse en estrategias de desregulación que, si bien son útiles para las necesidades de aquellas ET que precisan cuidar su imagen, son inútiles para la tarea de proteger los derechos de los trabajadores en la economía global. En este artículo he defendido el enfoque alternativo de la RELAPET a los estándares laborales internacionales y destacado algunas manifestaciones incipientes del mismo. Me he centrado en dos tópicos relacionados, pero analíticamente distintos, que son centrales para la RELAPET: los esquemas institucionales que facilitan la entrada de voces discrepantes, que puedan compensar el poder de las voces predominantes, y las estrategias transfronterizas de movilización capaces de aprovechar las oportunidades creadas por esas instituciones a través del uso de estrategias políticas dirigidas a exigirles a las empresas su responsabilidad ante la sociedad. En los párrafos que siguen concluyo resumiendo las pruebas positivas de un enfoque incipiente basado en la RELAPET que ofrece mi investigación y otros estudios recientes.

En primer lugar, en relación con las cuestiones relativas a los esquemas institucionales, el estudio del cumplimiento de los códigos en México y Guatemala y los recientes desarrollos en el campo de estudio apuntan hacia la aparición de iniciativas y mecanismos que comprometen a diferentes actores y que, si se incorporaran sistemáticamente dentro de

los esquemas de vigilancia y control, tendrían el potencial de facilitar la organización obrera y conseguir mejoras sostenibles de las condiciones laborales. Algunos mecanismos nos han mostrado ya que son particularmente indicados para promover las voces de los trabajadores como contrapoder. En lo que afecta individualmente a los trabajadores, la 
educación popular y los programas de formación, junto con los mecanismos para que los trabajadores puedan presentar directamente sus quejas, son herramientas útiles para elevar la conciencia acerca de los derechos laborales y presionar a las organizaciones coordinadoras de monitoreo para que intervengan en los casos de violación de los códigos. Algunas iniciativas en esta dirección son los programas de educación popular promovidos por la AFL-CIO en México, los programas de formación dirigidos por las ONG de HongKong en las fábricas de calzado de Adidas, Nike y Reebok en China, ${ }^{95}$ y el sistema del WRC para resolver las quejas individuales de los trabajadores en colaboración con las organizaciones locales. En relación a los trabajadores como colectividad, varias iniciativas nos permiten tener perspectivas optimistas de conseguir una protección mejorada de los derechos colectivos. Entre ellas estarían la participación de las organizaciones coordinadoras del monitoreo en campañas de organización transnacionales (como ilustran los casos de Kukdong y Choishin) y la experimentación con los comités de salud y seguridad ocupacional en las fábricas chinas gracias a los cuales los obreros toman una mayor conciencia de sus derechos y su poder. ${ }^{96}$

En el mismo sentido, algunos diseños e iniciativas ofrecen signos iniciales de la inclusión de las igualmente importantes voces discrepantes de los sindicatos y las organizaciones de apoyo a los trabajadores locales existentes junto a las voces dominantes de empresarios y sus organizaciones de apoyo. La construcción de capacidad en los sindicatos y las organizaciones locales de la sociedad civil es una característica constitutiva del WRC y de experiencias tales como las del programa SAI-ITGLWF en 10 países del mundo para educar a los líderes sindicales del sector del vestido sobre el uso de los códigos con el propósito de defender los derechos de los trabajadores. ${ }^{97}$

Además de prestar más atención a los derechos colectivos, las organizaciones de monitoreo individualmente y sus organizaciones coordinadoras necesitan abordar los permanentes problemas de independencia y transparencia. Aunque se ha hecho algún progreso, como por ejemplo la creación de unas pocas organizaciones de monitoreo independientes como COVERCO, o la publicación de algunos datos sobre las auditorías en los informes anuales de la FLA y en cuadros de seguimiento, el amplio uso de empresas de auditoría privadas y la opacidad de los sistemas de monitoreo plantean algunos de los

\footnotetext{
${ }^{95}$ MSN, “2003 Year End Review,” 8.

${ }^{96}$ Ibid.

${ }^{97}$ Kearney y Gearhart, "Workplace Codes as Tools for Workers.”
} 
obstáculos más serios a la RELAPET. Reemplazar a las empresas privadas de auditoría por organizaciones de monitoreo independientes, revelar la localización de las fábricas suministradoras (como se hace actualmente en el sistema WRC) y publicar los resultados de las auditorías son mecanismos institucionales específicos que conducen al tipo de datos fiables que son necesarios para que se incorporen sistemáticamente a los sistemas de monitoreo procesos de participación informada local e internacional.

Algunos Estados y organizaciones interestatales están experimentando también con esquemas institucionales que incorporan presiones balanceadoras en los niveles local, nacional e internacional. Por ejemplo, algunos gobiernos nacionales y locales en los Estados Unidos y Europa han introducido un requisito legal dentro las políticas para las licitaciones públicas conforme al cual los contratistas de la administración estatal tienen que informar a sus accionistas y al público interesado sobre asuntos laborales. ${ }^{98} \mathrm{Si}$ se expandiera para incluir el requisito de que las empresas estuvieran certificadas por medios independientes con el propósito de demostrar su cumplimiento de los estándares laborales internacionales, incluyendo su respeto a los derechos colectivos, estas políticas proporcionarían un fuerte apoyo al enfoque que tiene la RELAPET de los códigos de conducta. También, la Organización Internacional del Trabajo se ha ido involucrando lentamente en la vigilancia y el control, como atestigua la experiencia pionera de la supervisión de las fábricas del vestido camboyanas en el contexto del acuerdo textil entre Estados Unidos y Camboya. Como en el caso de la RELAPET, estos esfuerzos suplementan más que reemplazan el cumplimiento de los estándares de la OIT y las leyes laborales nacionales.

En segundo lugar, en relación con las cuestiones de la movilización política que son fundamentales en la RELAPET, el estudio de las campañas de Kukdong y Choishin muestra que el ejercicio de las estrategias políticas dirigidas a exigirles a las empresas responsabilidad ante la sociedad, al poner en funcionamiento procedimientos y normas institucionalizadas con los cuales los fabricantes globales se han comprometido, puede ser una herramienta útil para aquellas RATN que buscan impulsar la causa de los derechos laborales internacionales. Como lo expresa Evans en su estudio general sobre las formas de globalización contrahegemónicas, incluso instituciones que no fueron originalmente diseñadas para proteger efectivamente las necesidades de los trabajadores, como es el caso

\footnotetext{
${ }^{98}$ MSN “2003 Year End Review,” 8.
} 
de la mayoría de los códigos de conducta, pueden convertirse aun así en "puntos equilibrantes de influencia política", 99 siempre y cuando los actores contrahegemónicos exploten la distancia que separa el discurso de la práctica mediante estrategias políticas dirigidas a exigirles a las empresas que cumplan con su responsabilidad social. Junto con esquemas institucionales apropiados, estas estrategias pueden contribuir a la lucha actual contra el trabajo en las maquilas en la economía global.

\footnotetext{
${ }^{99}$ Peter Evans, "Fighting Marginalization with Transnational Networks: Counter- Hegemonic Globalization," Contemporary Sociology 29, no. 1 (2000): 230-41, 235.
} 